Portland State University

PDXScholar

5-8-1992

\title{
The Development of a Predictive Model of Pretrial Misconduct
}

Donald R. Trapp

Portland State University

Follow this and additional works at: https://pdxscholar.library.pdx.edu/open_access_etds

Part of the Criminology and Criminal Justice Commons, and the Psychology Commons Let us know how access to this document benefits you.

Recommended Citation

Trapp, Donald R., "The Development of a Predictive Model of Pretrial Misconduct" (1992). Dissertations and Theses. Paper 4574.

https://doi.org/10.15760/etd. 6458

This Thesis is brought to you for free and open access. It has been accepted for inclusion in Dissertations and Theses by an authorized administrator of PDXScholar. Please contact us if we can make this document more accessible: pdxscholar@pdx.edu. 
AN ABSTRACT OF THE THESIS OF Donald R. Trapp for the Manter of Science in Psychology presented May 8, 1992.

Title: The Development of a Predictive Model of Pretrial Misconduct.

APPROVED BY THE MEMBERS OF THE THESIS COMMITTEE:
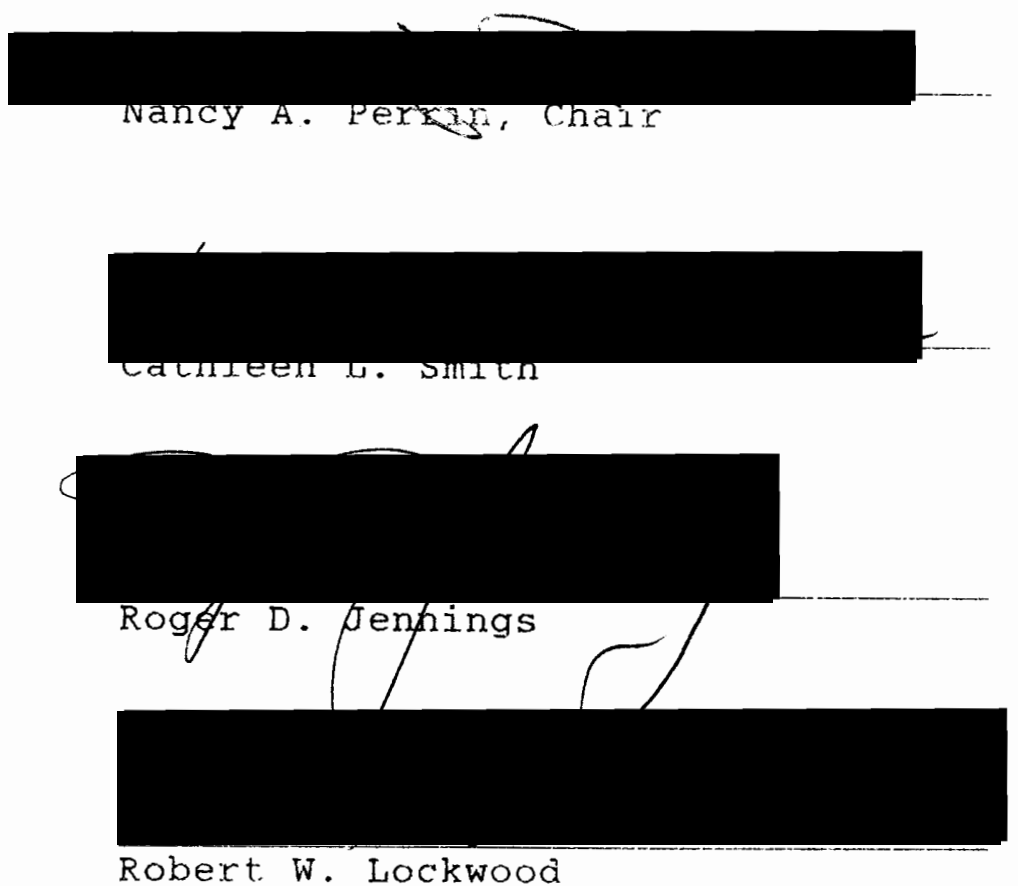

The problem of jail overcrowding has forced corrections officials and jail administrators to examine ways jn which to better manage available jajl space. 
Pretrial release and detention policies have been a target of this examination as pretrial defendants typically account for 50\% of a jail's population. Standards for pretrial release exist, but their administration varies by jurisdiction. The impact of jail overcrowding on pretrial release policies has been to decrease the time available to render a decision. Recent efforts to standardize pretrial release standards in Oregon have not addressed the issue of expediency. The current study examines pretrial misconduct (failure to appear in court and rearrest) with regard to information that is available to jail personnel and release office personnel at the time of arrest, with the specific intent to develop a predictive model of pretrial misconduct that will function as an initial risk assessment.

Six hundred defendants arrested in washington County, Oregon during 1991 served as subjects. The results indicated that $90.9 \%$ of all defendants arrested are released pending trial, and that $22.7 \%$ of those released engaged in pretrial misconduct. The results of the loglinear model-building indicated that the variables prior failure-to-appears, employment, and age were the best predictors of pretrial misconduct. The construction sample ( $n=395)$ accurately predicted $94.5 \%$ of the observed pretrial misconduct compared to $90.7 \%$ for the validation 
sample $(\mathrm{n}=150)$. The loglinear analysis yielded 16 typologies (based on the variables included in the model) by which defendants could be ranked as to their risk of pretrial misconduct. Spearman Rank order coefficents for the construction and validation samples were .847 and .626 respectively. Data were also collected on detained subjects. A Chi-square test using detained with released subjects by typology indicated that the categories are not independent $(p<.01)$. Further examination indicated that the detained subjects did represent higher risks of pretrial misconduct as estimated by the typologies. The results also indicated that defendants currently on probation or parole were more likely to detained than other defendants.

The results do not reject the assumptions by sturz (1962), whose Manhattan Bail Project is the basis for pretrial release, that persons with strong ties to the community may pose the least risk of pretrial misconduct. The results also found sex and ethnic differences with regard to pretrial misconduct. The sex differences may have been confounded by age and crime type; however, the ethnic differences may reflect a systemic inability to communicate with Hispanic offenders. 
THE DEVELOPMENT OF A PREDICTIVE MODEL OF PRETRIAL MISCONDUCT

by

DONALD R. TRAPP

A thesis submitted in partial

fulfiliment of the requirements for the degree of

MASTER OF SCIENCE

in

PSYCHOLOGY

Portland State University

1992 
TO THE OFFICE OF GRADUATE STUDIES:

The members of the Committee approve the thesis of Donald R. Trapp presented May 8, 1992.

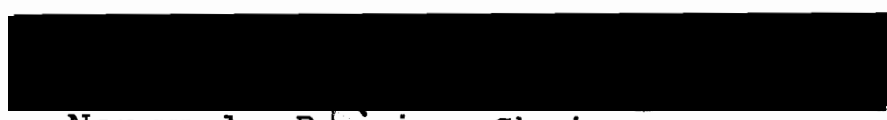

Nancy A. Pergin, Chair

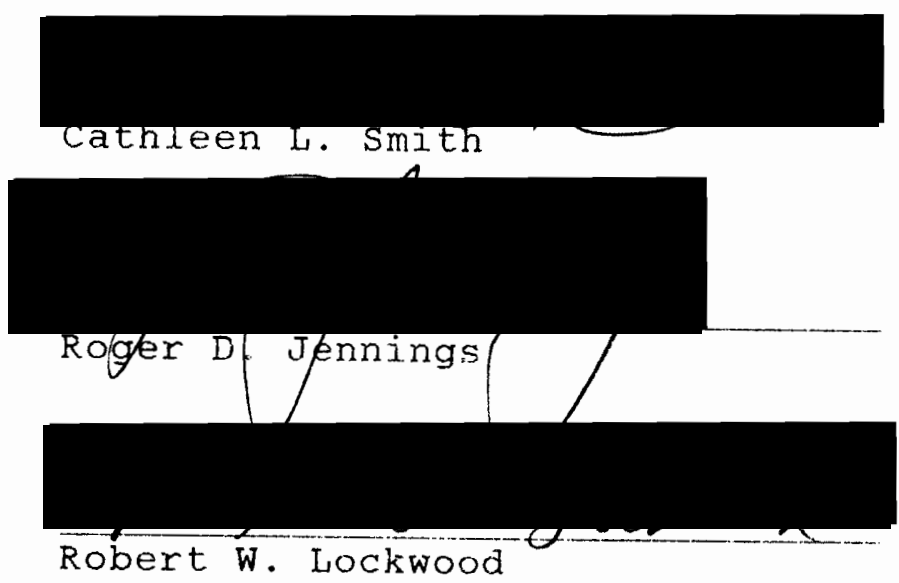

APPROVED:
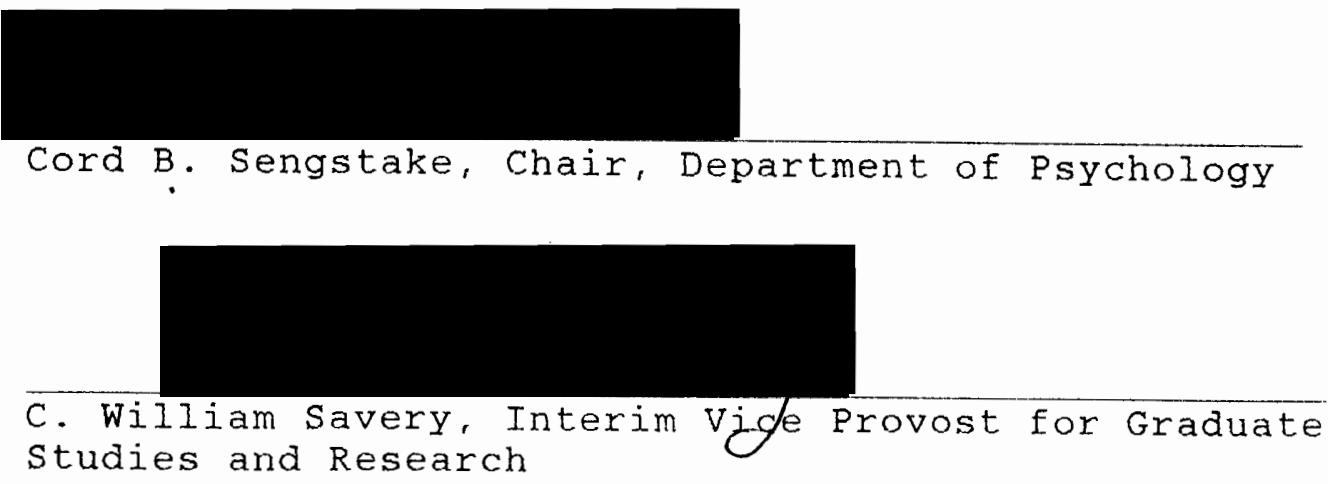


\section{ACKNOWLEDGEMENTS}

This thesis could not have been completed without the support and assistance of the Washington County courts and Department of Public safety. The author gratefully acknowledges the Honorable Michael J. MC Elligott for allowing this project to be conducted. Special thanks is due for: John Hutzler, Justice Services Coordinator, for his technical support; Scott Steele, Release Assistance Officer; and Captain Michael Conley, Department of Public safety, for their input and support of this project.

A special debt of gratitude is owed to Robert Gates, Manager, Washington County Restitution Center. Without his support of both the project and its author, the current study could not have been completed.

Special recognition is due for Kathi A. Ketcheson, whose tremendous emotional and technical support made this project possible.

This Thesis is dedicated to the memories of two men whose influence has been profound on both this project and its author: my mentor, the late Dr. David L. Cressler; and my father, the late James C. Trapp. 
TABLE OF CONTENTS

PAGE

ACKNOWLEDGEMENTS $\ldots \ldots \ldots \ldots \ldots \ldots \ldots \ldots \ldots \ldots \ldots \ldots \ldots \ldots$

LIST OF TABLES $\ldots \ldots \ldots \ldots \ldots \ldots \ldots \ldots \ldots \ldots \ldots \ldots \ldots \ldots \ldots$

LIST OF FIGURES $\ldots \ldots \ldots \ldots \ldots \ldots \ldots \ldots \ldots \ldots \ldots \ldots \ldots \ldots \ldots \ldots$

CHAPTER

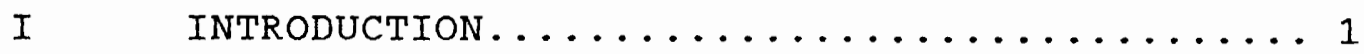

II OVERVIEW OF THE PROBLEM............. 3

III ISSUES IN PRETRIAL RELEASE.......... 12

The Current Model............ 14

IV PSYCHOLOGICAL ISSUES.............. 20

Socioanalytic Theory........... 21

$\mathrm{V}$ STATEMENT OF THE PROBLEM AND PROPOSED RESEARCH

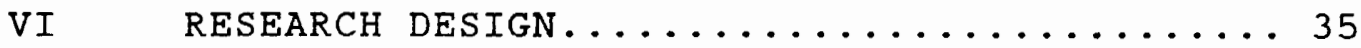

Developing the Model........... 35

Loglinear Analysis........... 36

Assessing the Impact of The Model... 41

Method....................44

Subjects............... 44

Materials................ 45

Procedure...............45 
RESULTS .......................... 47

Descriptive statistics........... 47

Data Modifications.............. 49

Loglinear Analysis............... 54

Constructing the Model...........69 69

Validating the Model.............6 69

VIII $\quad$ DISCUSSION. ................... 76

The Predictive Model.............76

Sex and Ethnic.................. 81

The Detained Subjects........... 85

IX CONCLUSIONS AND RECOMMENDATIONS......... 88

REFERENCES........................... 92

\section{APPENDICES}

A POPULATION RELEASE SCORES............... 96

B RECOGNIZANCE AGREEMENT................... 98

C INITIAL RISK ASSESSMENT................ 101

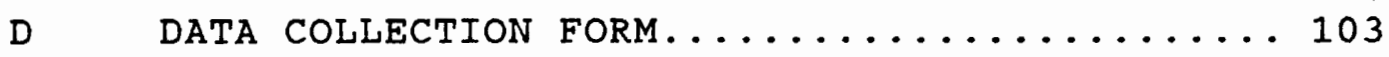




\section{LIST OF TABLES}

TABLE

PAGE

I Release Detention and Pretrial Misconduct

Rates...................... 48

II Distribution of the Independent Variables

by Selected Groups................ 50

II Crosstabulation of the Independent Variables

by the Dependent Variable Pretrial

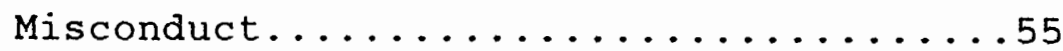

IV Loglinear Analysis of Pretrial Misconduct in

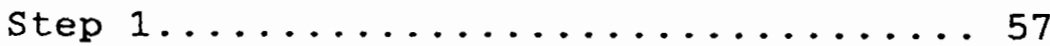

V Loglinear Analysis of Pretrial Misconduct in

step $2 \ldots \ldots \ldots \ldots \ldots \ldots \ldots \ldots \ldots \ldots$

VI Loglinear Analysis of Pretrial MIsconduct in

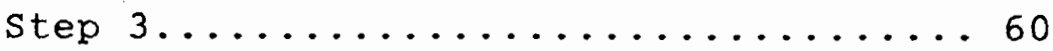

VII Loglinear Analysis of Pretrial Misconduct in

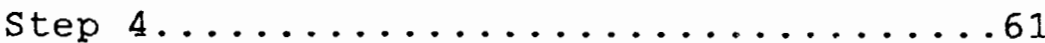

VIII Loglinear Analysis of Pretrial Misconduct in

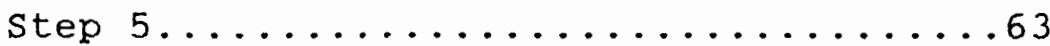

IX Loglinear Analysis of the Tentative Model of

Pretrial Misconduct in step $6 \ldots \ldots 65$

$X$ Loglinear Analysis of the Tentative Model of

Pretrial Misconduct in step $7 \ldots \ldots 66$ 
vii

TABLE

XI Loglinear Analysis of Pretrial Misconduct in

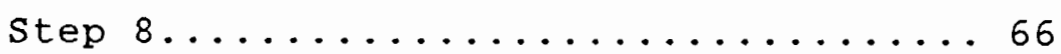

XII Parameter Estimates for the Selected Model...68

XIII Predicted and Observed Rates of Pretrial

Misconduct in the 16 Typologies from the Construction Sample........... 70

XIV Predicted and Observed Rates of Pretrial

Misconduct for the Construction and

Validation Samples............ 72

XV Predicted and Observed Frequencies of

Pretrial Misconduct for the Construction

and Validation Samples by Typology.... 73

XVI Frequency of Detained and Released Subjects

Across the 16 Typologies.......... 75 


\section{LIST OF FIGURES}

FIGURE

PAGE

1. Schematic of the Release/Detention Process.. 9

2. Multidimensional Contingency Table....... 38 
CHAPTER I

\section{INTRODUCTION}

Washington county, the third most populous county in Oregon, has been the recipient of rapid population and economic growth since the early $1980^{\prime} \mathrm{s}$. This growth also has been felt in the area of crime, where the increase in crime has been consistently larger than the increase in population (Oregon Law Enforcement Council, 1989). During the past decade, the 180 bed county jail and 88 bed restitution center have been able to accomodate these increases. In recent years however, release and detention policies have been modified to adjust for increases in jail population. These modifications have included: releasing more defendants pending trial, and releasing sentenced offenders prior to the completion of their sentence.1 The policies regarding the release of either sentenced or unsentenced offenders in Washington County are not empirically based. While the release decisions are based

1 Modifications utilized in other Oregon Counties include:close street supervision, where defendants are closely monitored pending trial; and cite and release policies, where defendants are cited in lieu of arrest. 
on standard criteria, the evaluation of those criteria is purely subjective. Precluding the construction of new facilities, which is currently being discussed, county officials are seeking ways to better manage the available jail space.

Because $50 \%$ of the jail's population are defendants awaiting trial, pretrial release policies have been targeted for research. ${ }^{2}$ County officials have afforded this author the opportunity to conduct such research, with the ultimate intent of examining how policy changes could impact jail overcrowding, and with specific regard to how changes in pretrial release can reserve more jail space for sentenced offenders while maintaining the integrity of the pretrial release system. The author submits that the first stage of this policy analysis should be the development of a predictive model of pretrial misconduct.

2 The other 50\%, which are sentenced offenders, are regulated by a "route out" system. This system rates offenders eligibility for furlough, early release, or transfer to minimum security. The system utilzes a Burgess-type scale to rate offenders on various criteria; however, the scale has never been validated. 


\section{CHAPTER II}

\section{OVERVIEW OF THE PROBLEM}

Unconvicted offenders in the nation's jails have been a source of concern for both law enforcement officials and lawmakers. The population in the jails has increased at an average rate of $5 \%$ each year since 1981 (U.S. Department of Justice, 1988). These increases have created a situation where jails in $28 \%$ of the nation's various jurisdictions are under court order to limit population (Pretrial Reporter, 1988). Even with the construction of new facilities, corrections officials are focusing their attention on ways to manage these increasing populations. Since at any given time, $52 \%$ of a jail's population are defendants awajting trial, pretrial release programs are being examined with regard to their ability to assist in jail space management.

Pretrial release, as the extension of an individual's right to be adjudged as innocent until proven guilty, is available to every defendant except those accused of crimes punishable by death or life imprisonment. In addition, the only criteria that may be used in making release decisions 
are facts that would indicate a person's propensity not to appear in court as ordered.1 Further, the potential risk that a defendant may pose to the community if released, may not be used as a factor in release decisions (Toborg, 1981; Clear \& Cole, 1986; Pretrial Reporter, 1988). Only those defendants who meet specified criteria will be granted pretrial release. Despite this limitation, the potential dangerousness of defendants is often considered in release decisions (Toborg, 1989). In addition, the 1984 Crime Prevention Act authorized the detention of defendants if it was alleged that no condition of release could ensure a court appearance or the safety of the community. This legislation gave jail administrators an opportunity to reduce failures-to-appear and crimes committed while on pretrial release without advocating that such dangerousness be proven (Morris \& Miller, 1985).2

1 These facts, as prescribed by Oregon Revised Statutes (135.230) are: employment status, family ties in the community, local residence, current charge (seriousness), previous record, personal references, and previous performance on pretrial release.

${ }^{2}$ Washington County has recently utilized a scale to assess the potential danger a defendant may pose to the community if released (see Appendix A). There is no evidence suggesting that the scale has been validated. 
The criteria used to determine a defendants' eligibility for release were developed during the Manhattan Bail Project (Sturz, 1962). This study established that large numbers of defendants could be released pending trial on their own recognizance, or promise to return. sturz (1962) asserted that pexsons who had strong ties to the community would be better release risks than persons lacking those ties. The Manhattan Bail Project identified six criteria that facilitated that process: employment status, family ties in the community, local residence, current charge (seriousness), previous record, personal references, and prior performance on pretrial release. These criteria are often referred to as the VERA Scale; and, as evidenced by their similarity to oregon law, are the basis for pretrial release in the United States. While Sturz's assumption and identified criteria (the VERA Scale) guide the administration of pretrial release, there is neither an identifiable typology of high-risk defendants (in terms of failure to appear), nor are the criteria conducive to objective evaluation. This is evidenced by Toborg's (1981) findings that many jurisdictions utilize a subjective assessment method to determine potential release risk. Further, there is a demonstrated lack of record keeping by pretrial release 
programs that would allow for the development of an empirical basis for their release decisions (Toborg, 1981; 1989; Pretrial Services Resource Center, 1990). The records and data that are available are the result of periodic descriptive statistics compiled by the U.S. Department of Justice.

However, given the shortage of jail space, there is considerable pressure to develop effective jail space management techniques. This is evidenced by Toborg's (1989) effort to develop statewide pretrial release standards for the state of Oregon, a project that developed at the behest of the oregon Legislature. It was the intent of the legislature to develop release policies that would maximize the number of persons released while minimizing the incidence of pretrial misconduct (failure to appear and rearrest). The impact of pretrial release policies on the jail population may be viewed both statistically and procedurally.

statistically, this impact may be assessed through the percentage of defendants who are released pending trial (release rate). As more defendants are released pending trial, more jail space becomes available for sentenced offenders. The release rate, however, must be viewed with respect to $\rightarrow$ percentage of defendants who fail to appear in court as ordered (FTA rate), and the percentage who are 
rearrested while awaiting trial (rearrest rate). These two measures can be combined, and are then referred to as the pretrial misconduct rate (Toborg, 1981). The misconduct rate is a measure of the effectiveness of the pretrial release program's decision process. Each incidence of pretrial misconduct is a release decsion error, specifically a Type I error. ${ }^{3}$

In 1990, the Pretrial Services Resource Center (PSRC) conducted a study of pretrial release. The study sampled 47 jurisdictions from across the country and included 29,404 subjects (defendants). Among other results, the study found that: the mean release rate was $66 \%$, with a range from $30.1 \%$ to $90.2 \%$; and the mean for the pretrial misconduct rate was $41 \%$, with a range from. $9 \%$ to $53.5 \%$.

In this study, no attempt was made to establish the validity of the predictor (VERA Scale) to the criterion (pretrial misconduct). Since the development of the VERA scale in 1962, few studies have attempted to examine this relationship. Two of those studies /Gottfredson, 1974 ; Toborg, 1989), have found that relationship to be $R^{2}=$ $.15(p<.01)$ and $R^{2}=.1478$ (significance not available)

${ }^{3}$ Type II exrors, which would represent aetaining a defendant who would not engage in pretrial misconduct, are not addressed by the Iiterature as data from detained subjects can not be used to predict pretrial misconduct. 
respectively. While the validity level may be due to the VERA scale items and the subjective manner in which these items are interpreted, it may also be affected by the lack of available jail space. As can be demonstrated by a procedural overview, this lack of space affects the number and type of defendants who may be detained, as well as the time allowed to render a decision.

Procedurally, pretrial release has not been able to adjust to the increased volume of defendants. Figure 1 illustrates the normal release process wherein:

1) based on the severity of the offense, a defendant's eligibility for pretrial release is determined4;

2) if the defendant is not immediately eligible for release, and the court must set conditions for release, the defendant is then interviewed by a Release Assistance officer (RAO). The VERA scale information obtained in this interview is then verified;

3) if the defendant is eligible, pretrial release may be obtained through a recognizance agreement (see Appendix B), or by posting bail;

${ }^{4}$ State or local law provides discretion as to the eligibility of defendants, charged with various offenses, to gain release. This discretion may be influenced by a lack of jail space or a court order to limit population in the jail (Toborg, 1989; Pretrial Reporter, 1988). 


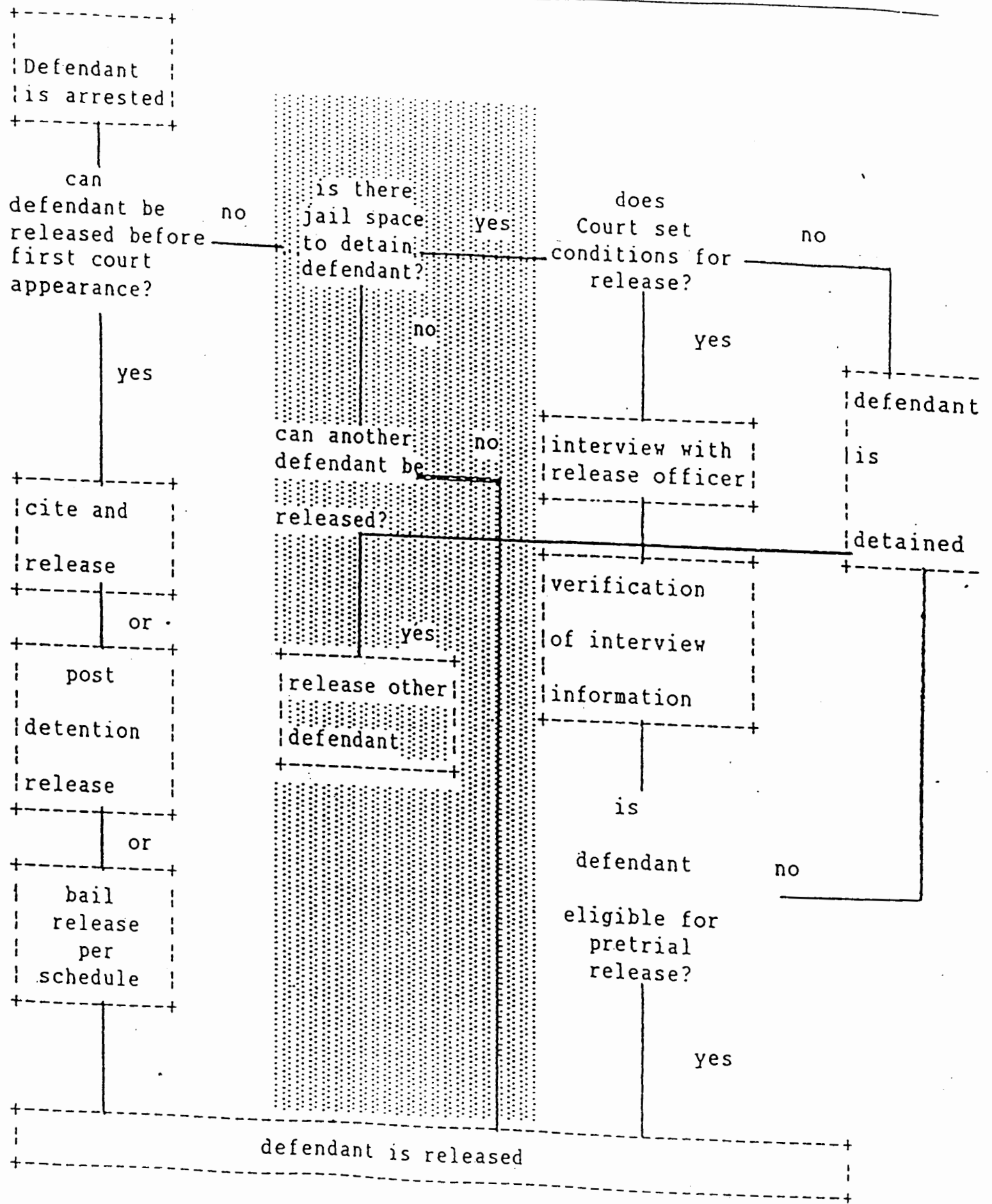

Figure 1. Schematic of the release/detention process. 
4) if the defendant is not eligible, release will not be granted until the arraignment. By law, this arraignment must take place within 72 hours of arrest.

However, when a particular facility is operating at or near its capacity, this process is altered. The shaded area of Figure 1 illustrates how the lack of jail space impacts this process. Under these circumstances, if there is no jail space, a release decision is imminent, regardless of the fact that the released person may not have qualified for release under normal conditions, or may not even have undergone the interview/verification process. Further, as the normal interview/verification process may take several hours or longer to complete, jail personnel are forced to render release decisions that are based on minimal information.5 The exact frequency of this circumvented process is not precisely known, but would be dependent upon the specific characteristics of a jurisdiction such as: amount of jail space available, number and availability of RAO's, and policies regarding release (e.g., crime seriousness, emphasis on bail releases). Toborg (1989), in an analysis of pretrial release in oregon, found

${ }^{5}$ Oregon Revised statutes (135.010) provides each defendant an opportunity to appear before a magistrate within 36 hours of arrest to address the issue of release. 
that several counties do not have RAO's on staff. In addition, defendants released in this altered manner are usually excluded by research, due to the sparcity of information that is available from them. However, these defendants may be included in general estimates of pretrial misconduct (Pretrial Services Resource Center, 1990). Further, because defendants released due to a lack of jail space do not undergo the normal release process, any increase in the validity of the predictor variables (VERA Scale) would not alleviate the problem of defendants being released without an appropriate assessment of their risk of pretrial misconduct. Thus, there are two majox issues confronting pretrial release with regard to either impacting jail overcrowding or to improving its own effectiveness:

1) a lengthy release process that is prone to being circumvented; and,

2) predictor variables of limited validity. 
CHAPTER III

\section{ISSUES IN PRETRIAL RELEASE}

The amount of time required to render a release decision has never been addressed in the literature as a source of concern. Toborg (1989) asserts that the release process as it is, is essential. ${ }^{1}$ However, given that an undetermined number of defendants are eluding this process, and that decreasing jail space threatens to increase this number, it would appear that some effort to reduce the time needed to conduct a risk assessment would be prudent.

In an analogous situation, the oregon state Department of Corrections has developed an initial risk assessment instrument for classifying parolees and probationers. This instrument (see Appendix C) is a Burgess Type scale wherein: unitary weights are assigned to each category of a scale based on the success rate or other correlational measure related to that variable; these weights are summed to provide a scale score (Burgess,

1 This lengthy process is also prescribed under oregon Law (ORS 133.235). 
1928; cited in Van Alstyne \& Gottfredson, 1978). In the case of the initial risk assessment, the scale score will indicate the level of supervision that is most appropriate for that person. The benefits of this instrument in assessing the potential risk of a parolee or probationer are: the instrument utilizes information that is routinely contained in the subject's file, (e.g., criminal history, social history), and information about the current offense; and, the instrument can be completed within 30 minutes.

With regard to pretrial release, an initial risk assessment similarly conducted would allow for the interview/verification process to be postponed, as the risk assessment would be based on information available from the defendant's file. In addition, since the information would be obtained from documented sources instead of via the interview process, the quality of the data would not be threatened by defendants misrepresenting themselves.2

While the initial risk assessment approach has apparent benefits from a procedural perspective, these benefits could only be realized if the predictor variables are valid.

2 Toborg (1989) has suggested that the predictors used in the traditional process would have to be reviewed and reconfigured periodically to reduce this source of error. 
THE CURRENT MODEL

As previously stated, the basis for pretrial release in the United States is the Vera Scale developed during the Manhattan Bail Project (Sturz, 1962). In this study, it was purported that defendants with strong ties to the community were less likely to engage in pretrial misconduct. The strength of these ties were alleged to be estimable from the following criteria: employment, current residence, current charge, prior record, prior performance on pretrial release, and personal references. Using these criteria, the RAO conducts a structured interview to develop a profile of the defendant. Based on this profile, an assessment of risk is made which leads to a release decision. The observation by Toborg (1981) that the VERA Scale is not a true scale, but criteria that are subjectively interpreted, suggests that pretrial release decisions are clinically as opposed to statistically derived. However, the issue is not whether clinically derived decisions are more valid than statistically derived decisions, rather which are more expedient.

The current release process (clinical method) has been demonstrated to be more time consuming than the jail space shortage will allow. This is not to suggest that the VERA 
Scale items are also inappropriate in assessing risk of pretrial misconduct. The initial risk assessment previously discussed is proposed as a remedy to the time constraint imposed on the release process. To be effective and expedient, the initial risk assessment will utilize the most valid predictors of pretrial misconduct in a format that will preclude subjective assessment, and the risk assessment will be statistically derived. Towards the development of a predictive model of pretrial misconduct, it would be prudent to examine the VERA scale items for their possible inclusion in such a model.

The VERA Scale items most prone to subjective interpretation appear to be family ties in the community and employment. Assessing family ties in the community may involve an assessment of varied living situations: living with spouse, Iiving with family (extended family), living with other relative, or living alone. The RAO using these criterion values would have to rank- order each of these living situations into an interpretable scale. Toborg (1981) found that rearrested defendants were more likely to be Iiving with their parents. In 1989, Toborg found that the highest rate of pretrial misconduct was by defendants who were seperated from their spouses (29.5\%), while the lowest rate was among defendants who were divorced (14.3\%). 
Similarly, in the case of employment, Toborg (1989) found that the rate of pretrial misconduct did not vary between the empioyed defendants (35.15\%) and the unemployed defendants (34\%). Unemployed defendants were only more likely to be detained than employed defendants (19.8\% unemployed detained compared to $9.7 \%$ employed detained) (Toborg, 1981). The fact that more unemployed defendants were detained may contribute to the similarities in pretrial misconduct for those two groups, as the higher rate of detention for unemployed defendants may have mitigated the effect due to employment. However, employment may be a good predictor of pretrial misconduct when viewed in relation to other predictors.

The most unambiguous variables appear to be those which preclude subjective assessment, e.g., criminal history variables such as: number of prior arrests/convictions, and probation/parole status. Toborg (1981) has found that defendants who engage in pretrial misconduct were more likely to have had more prior arrests, and to have been on probation or parole at the time. Toborg (1989) also found that the risk of pretrial misconduct increased with the number of prior arrests. As to the severity and type of the offense, Toborg (1981) has developed a unique approach to grouping crime types. As the felony/misdemeanor dichotomy is based on the 
sanctions that the state may impose upon conviction, Toborg's taxonomy provides homogenous crime groups. The taxonomy used by Toborg (1981) divided crimes into the following groups:

*Crimes Against Persons (murder, manslaughter, forcible rape, robbery, aggravated assault, assault, and arson):

*Economic Crimes (burglary, larceny, theft, forgery, fraud, embezzlement, stolen property);

*Drug Crimes laistribution or possession of narcotics or marijuana):

*Crimes Against Public Morality (prostitution, sex offenses, gambling, liquor law violations, drunkeness);

*Crimes Against Public order (weapons, driving while intoxicated, disorderly conduct, vagrancy, minor local offenses):

* Miscellaneous Crimes (failure to appear, violations of parole, offenses against family and children, malicious destruction, conspiracy, and other crimes)

Using this taxonomy, Toborg (1981) found that persons charged with economic crimes were more likely to engage in pretrial misconduct than persons charged with other offenses. 
In summary, the current release process is based on clinically derived assessments of risk. The criteria used to estimate this risk are the VERA Scale items: employment status, family ties in the community, local residence, current charge, prior record, personal references, and previous performance on pretrial release. The Release Assistance Officer utilizes these criteria as a guide towards estimating the potential release risk, as the VERA scale is only a set of criteria which is employed in a discretionary manner.

The lack of jail space has impacted the pretrial release process by forcing the release of defendants prior to contact with a RAO, and initiating analyses of the release process which have demonstrated a low level of validity of the predictors (the VERA Scale) to the criterion (pretrial misconduct).

In view of this low level of validity, it may be suggested that there is a lack of empirical support for the assumption by sturz (1962) that persons with strong ties to the community would pose the least risk of pretrial misconduct. Further, these methods do not characterize the risk potential of pretrial defendants. In comparisons between offenders and non-offenders, and violent and non-violent offenders, Hogan \& Jones (1983) have observed 
differences along variables that may be objectively evaluated and that are routinely maintained in a defendants' file; moreover, they suggest that these differences are indicative of different personality traits of offenders and non-offenders. As these differences are both measurable and suggestive of behavioral propensities, it is suggested that they are conducive to the development of a predictive model of pretrial misconduct. 
CHAPTER IV

PSYCHOLOGICAL ISSUES

As pretrial misconduct is a specific type of criminal behavior ${ }^{1}$, it may be viewed in terms of general theories of criminal behavior. Similarly, Sturz's (1962) assumption that persons with strong ties to the community are less likely to engage in pretrial misconduct may be more broadly interpreted as the assumption that persons who have demonstrated their conformance to the social order by maintaining gainful employment, maintaining a stable residence, having little or no priox contact with the criminal justice system, and having a social support system within the community, would be least likely to engage in pretrial misconduct (criminal behavior). Thus, in seeking to develop a predictive model of pretrial misconduct, it would be necessary to identify the differences between offenders and non-offenders. Hogan and Jones (1983) have been able to identify differences between offenders and

1 Failure to Appear $I$ is a Class C Felony in Oregon (ORS 162.205). 
non-offenders, and between violent and non-violent offenders. These differences are observable using objectively defined variables and interpretable via research in Socioanalytic Theory.

\section{SOCIOANALYTIC THEORY}

There is an emerging perspective in the study of criminal behavior that questions the appropriateness of the established relationship between deviant and criminal behaviors. Although the deviance perspective may be appropriate to describe observable behaviors, the inference that the motivational factors are also deviant may not be appropriate (Eysenck, 1964; Merton, 1968; Hogan \& Jones, $1983)$

It has been suggested that the behavioral diversity that spans both licit and illicit behaviors is an expected product of a society where there is a large variance in educational and vocational opportunities, in addition to an array of attitudes, styles, and tastes; moreover, that this diversity is testimony to the robustness and adaptability of human behavior (Lemert, 1951; cited in Jones \& Gibbons, 1983; Merton, 1968). 
Rather than emphasizing the differences between observable behaviors as a deviance perspective would prescribe, the diversity perspective emphasizes an examination of the similarities in the motives and aspirations between offenders and non-offenders. Research has demonstrated the relationship between lack of opportunity and crime and vice versa, thereby asserting the similarity in these motives and aspirations (Merton, 1968; Barley, 1984; Flango \& Sherbenou, 1976; De Fronzo, 1983). Hogan's Socioanalytic Theory provides a framework from which to view both licit and illicit behaviors. This Eramework is predicated on motives which are basic to all human behavior. Like Jones and Gibbons (1983), Hogan (1982) suggests that the diversity of human behaviors is most appropriately examined in terms of basic common elements. Socioanalytic Theory (Hogan, 1982) asserts that all human behavior is motivated by three primary needs: attention and approval, status, and predictability and order. Extending these behavioral motives to the concept of personality development, Hogan (1982) suggests that personality, as a product of social interaction, should be viewed from the perspective of both the actor and the 
observer. The observer's perspective refers to the social impression or reputation that the actor has created or established. As the actor's behaviors are directed towards the satisfaction of basic needs, the observer's feedback is essential so that the behaviors may be modified if they do not achieve the desired results (Aronson, 1980; Hogan, $1982)$

The actor's perspective refers to trine constructs that regulate an individual's behavior. Hogan (1982) has identified four constructs that exert this regulatory action:

Self-Concept; the view the individuals hold about theirselves and desires to convey to others, Self-Presentational Tactics; the various roles and behavioral repetoire available to the actor to convey the self-concept,

Reference Group; an internalized view of the expectations of significant others, whose approval or disapproval is of great concern to the actor,

Interpersonal Competence; the actor's ability to comprehend the expectations of observers and reference groups and modify self-presentational tactics, so as to accurately convey the self-concept.

It is suggested that the principle differences 
between criminals and non-criminals lie in the development and execution of these structures. Further, these differences become more apparent as personality becomes more stable (Hogan \& Jones, 1983).

With regard to these structures and their dynamic role in personality development, it is emphasized that:

Self-presentations are motivated by attempts to achieve attention and approval, while avoiding negative sanctions and disapproval from reference groups and significant others.

The self-presentational process is structured by self-images. Consequently, social interactions symbolically reflect the view of oneself to which one wishes others will subscribe.

Some people choose, or are forced to adopt, self-images that are less than ideal an even defensive.

There are individual differences in the degree to which people attend to internal (conscious) versus external (peer) reference groups. Maturity is typically associated with a balance between the two.

There are differences in the ability of individuals to project their self-image successfully. These differences are strongly related to success and popularity within groups. Over time, the aforementioned personality structures become automatic and unconscious; social conduct from the actor's point of view is typically experienced as natural and authentic (Hogan \& Jones, 1983, p.9.)

Optimally, personality development is guided by positive self-images. The self-presentational process serves to reflect this self-image, and is the mechanism by which personality develops further. Through the feedback from significant others and reference groups, 
self-presentations may be altered to achieve or maintain attention and approval. Though individuals vary in their ability to accurately project their self-images and interpret feedback from their peers, self-presentational tactics may preclude sociopathic or illicit behaviors, provided that role-playing abilities, allowing the individual to view him or herself as a social object, are present. Hogan \& Kurtines (1972; cited in Hogan \& Jones, 1983) have observed that role-playing abilities were significantly more deficient for criminals than non-criminals.

However, some individuals may have experienced less than optimal development. Thus, self-presentational tactics may be guided by negative self-images. As these individuals pursue status, attention and approval, and predictability and order, they may be more prone to sociopathic and illicit behaviors. The development of these traits would be precipitated by social failure or inadequacy.

Hogan \& Jones (1983) have postulated that individuals who have difficulty satisfying basic social needs may opt for a "trial and error" approach, wherein self-presentational tactics are modified, a new reference group may be selected, and the self-image impacted by the subsequent success or failure of this approach. "Acting 
out" and other disruptive behaviors may be indicative of this process (Hogan \& Jones, 1983). As social failure may bring alienation, insecurity or hostility (Merton, 1968; Aronson, 1980; Hogan, 1982), the corresponding behaviors would tend to be anti-social, impulsive, and defensive. Further, as the individual experiences frustration in attempting to satisfy basic social needs, aggressive behaviors would also occur (Aronson, 1980).

The development of a criminal or sociopathic personality would depend on how these behaviors and self-images are nurtured or extinguished as the individual interacts with peers, significant others, social institutions, and the community. It is suggested that anti-social, hostile, and criminal behaviors reflect self-images that form as a result of social inadequacy or failure (Hogan \& Jones, 1983). Merton's Anomie Theory (1968) asserts that this social inadequacy will result in behaviors that are contrary to the mainstream of society, and further, that these behaviors will be directed at rectifying perceived inequities. These inequities, in socioanalytic terms, could be in the form of $\mathrm{racial} / \mathrm{sexual}$ discrimination, or could be a perceived lack of attention and approval. The specific behavioral response would be dependent on the individual's self-concept, interpersonal 
competence, and prior experiences of social inadequacy. The socioanalytic perspective suggests that criminals experience more social failure and inadequacy than non-criminals. In addition, while anti-social or sociopathic tendencies would be predictable initial responses, the incidence of violent or aggressive behavior would occur in response to increased incidents of social failure. As there will be differences in the ability of individuals to modify their behavior in response to feedback from peers and significant others, it may be suggested that violent offenders may experience more difficulty in modifying their behavior to satisfy these needs, while non-violent offenders are slightly more adept. In comparisons between offenders and non-offenders using the Hopkins Personality Inventory (HPI), Hogan observed that offenders presented themseives as being more alienated, tough, reckless, and exhibitionistjc than non-offenders. These differences suggest that offenders have had difficulty in developing roles and identities that conform to the social order (alienated). This alienation may be due to deficiencies in role-taking ability, while the traits of toughness, recklessness, and exhibitionism are suggested to be indicative of criminal self-presentations (Hogan \& Jones, 1983), as they serve to 
minimize feedback and maximize reinforcement from their peers.

In comparisons between offenders charged with violent crimes and offenders charged with non-violent crimes, Hogan \& Jones (1983) observed that non-violent offenders were younger ( 28.9 vs. 35.7 years), and were less likely to have served prison sentences. The two groups did not differ significantly in marital status or prior criminal record.

The groups were also compared on the results of several personality trait scales. The violent offenders scored higher on measures of self-esteem, assertiveness, dogmatism, purpose-in-life, and social desirability. Non-violent offenders scored higher on a measure of anxiety. In addition, non-violent offenders claimed to be acting under great stress, and were more likely to admit guilt as a result (Hogan \& Jones, 1983).

The inference that younger offenders may be less secure in their roles, and may be developing new self-images and self-presentational tactics is supported by crime statistics which demonstrate that young (18-29 years) offenders account for $42 \%$ of all crime (U.S. Department of Justice, 1988).2 As older offenders account for

2 Offenders aged $30-34$ accounted for $12 \%$ of all arrests in 1988 in Oregon; ages 35-39, 10.9\%; ages 40-44, $3 \% ;$ and 40 and over $16 \%$. 
decreasing amounts of crime, it would appear that many young offenders opt for more conforming social roles over time. This may occur as a result of contact with the criminal justice system or other "feedback".

The fact that there was no difference in prior record between offenders charged with violent crimes and those charged with non-violent crimes, while there was a difference in prior incarceration is explainable in terms of the intervention of the criminal justice system. This intervention inadvertantly nurtures both the criminal behavior and the anti-social self-images. The economic, or property crimes, that younger offenders are more often involved with, are "cleared" at an average rate of $20 \%$ (U.S. Department of Justice, 1988). That is, only one in five of these crimes result in the arrest of the perpetrator. Thus, the offenders are "reinforced" four out of five times. In addition, the punishment, or aversion, that is meted out usually precludes incarceration, with probation being the preferred sentence. As the variable ratio schedule is more resistant to extinction, the behaviors persist.

Conversely, violent offenses are cleared approximately $50 \%$ of the time and usually result in incarceration. Given 
the similarity in prior records in the two groups, it may be inferred that the violent offenders are more stable in their roles, as evidenced by their persistence to engage in a behavior that yields harsh sanctions.

In addition, as the sentencing structure provides for increasingly harsh sanctions, offenders are systematically desensitized to its full impact, or even its intended goal. The sentencing structure will ensure that the offender has no opportunity to develop long-term social relationships with any group except other offenders. The result is that the offender population becomes the reference group for the individual. Status, attention and approval, and predictability and order, are now defined by the norms of that group. Within the offender population, there will be high status and low status criminals. Hogan \& Jones (1983) have observed that high status offenders are indistinguishable from non-offenders in terms of self-esteem.

The profile that develops suggests that younger, non-violent offenders are less secure in their roles as criminals, as evidenced by their higher level of anxiety and lower level of self-esteem. The younger offenders were also more likely to admit acting impulsively (Hogan \& 
Jones, 1983). This impulsiveness is evidenced by Toborg's (1981) findings that $40 \%$ of the defendants who failed to appear returned to the court on their own. This would support the assertion that individuals may choose roles that are not ideal. Thus, higher levels of anxiety and impulsiveness would be expected.

In terms of pretrial misconduct, the anxious, impulsive tendencies of the younger, non-violent offenders would appear to be most conducive to this type of behavior. It is inferred that these offenders are more likely to be "experimenting" with a new role and its associated behaviors. With the anxiety and impulsiveness associated with unfamiliarity, the specific behavior of these individuals, especially under very stressful circumstances: i.e., appearing in court, possible jail/prison sentence, severe embarassment, would be hard to predict. 
CHAPTER V

STATEMENT OF THE PROBLEM AND PROPOSED RESEARCH

Pretrial release programs have been unable to respond to jail overcrowding due to a lengthy release process that is prone to circumvention. One solution is to conduct a risk assessment on defendants when they are processed into the jail. This assessment should utilize information that is currently available to the jail staff at that time. In that way, if the current release process wilj not be completed before a release decision is imminent, that release decision would be based on some form of standardized and objective criteria.

It has also been shown that pretrial release programs are operating with predictor variables of limited validity. A true estimation of this validity is confounded by the subjective manner in which these variables are interpreted. Further, the assumption by sturz (1962) that pretrial misconduct is a function of an individual's ties to the community may also be of limited validity. Research in 
socioanalytic theory has identified differences between offenders and non-offenders and between violent and non-violent offenders along variables similar to the VERA scale. It is proposed, that these differences suggest that personality differences, not ties to the community, may be significant in predicting pretrial misconduct. specifically, pretrial misconduct as an impulsive behavior perpetrated by individuals developing criminal self-presentations and, subsequently, criminal self-images. Utilizing variables suggested by research in socioanalytic theory and from Toborg's $(1981,1989)$ research in pretrial misconduct, it is proposed that a predictive model of pretrial misconduct can be developed. Moreover, it is proposed that this model, being conducive to objective assessment, will be able to supplant the VERA Scale as the basis for pretrial release decisions.

Towards this end, it is hypothesized that pretrial misconduct will vary by the following variables:

Derived from Research in Socioanalytic Theory

1) Age, with younger offenders (18-29 approximately) posing the highest risk; 
2) Crime Type, with persons charged with economic (non-violent) crimes posing the highest risk;

Derived from the Vera scale

3) Prior Arrest Record, with the incidence of misconduct increasing with the number of arrests.

4) Parole/Probation status, with probationers and parolees posing higher risks than non-probationers/parolees.

Additional information regarding the sex, ethnic, employment status, current residence, and prior incarceration of each subject will be collected and analyzed as to its relationship to pretrial misconduct.

The current study will vary from previous efforts to develop a predictive model of pretrial misconduct in that the proposed initial risk assessment will utj.lize only that information from each defendant that is routinely available at the time of the arrest, and will not be derived from direct contact with the defendant. 
CHAPTER VI

\section{RESEARCH DESIGN}

There are two major goals to the proposed research: 1) to develop a predictive model of pretrial misconduct; and,

2) to assess the impact of such a model on current release and detention policies in Washington County, Oregon.

\section{DEVELOPING THE MODEL}

The development of the predictive model will differ from previous efforts with respect to the sample population, and the variables that will serve as predictors. The sample population will be defendants who have been arrested in Washington county and are eligible for pretrial release. The sample will include defendants who gain release without the benefit of the standard release process, as well as defendants who have been detained as a result of current release/detention practices. 
The variables that will serve as predictors will include those suggested by research in socioanalytic theory, e.g., type of crime, age, prior incarceration, and variables that are collected routinely by jail personnel, e.g., sex, ethnic, prior record, probation or parole status, employment and current residence. From these variables, a predictive model of pretrial misconduct will be developed using Log-Linear Analysis.

\section{LOG-LINEAR ANALYSIS}

Log-Linear Analysis is a model building technique that subsumes a variety of similar techniques, including multiple regression and multiple cross-tabulation. Log-Linear has been designed to overcome the shortcomings of these and related techniques, specifically under conditions when: the dependent variable is dichotomous and can not be considered as normally distributed; and the independent variables are categorical and also cannot be considered to be normally distributed or to have equal variance. Under these conditions, loglinear analysis has been demonstrated to be an effective model building technique (Benda, 1989; Fuchs \& Flanagan, 1980; Ott \& Markewich, 1985). 
Log-Linear is conducted via a multi-way contingency table (See Figure 2), where all the independent variables are crosstabulted with the dependent variable, and the number of cases in each cell is the frequency of the dependent variable for that level of the independent variable. Log-Linear calculates cell frequencies (observed and expected) to determine the effect of each of the independent variables and their interaction with the dependent variable.

Log-Linear calculates parameter estimates for each of the main effects and interactions in a manner similar to analysis of variance. Using the natural log of the cell frequencies instead of the actual frequency, the parameter estimates are the average log of the frequency for a main effect or interaction minus the grand mean of the frequencies in the table. Thus, the parameter estimates represent the increments or decrements from the grand mean due to a specific variable or interaction. As the parameter estimates repesent the total variation from the grand mean due to a specific variable, the estimates will sum to zero across all levels of a variable. The parameter estimates function like regression coefficients in that their sums provide an interpretable value of the dependent variable. 
Observed Expected

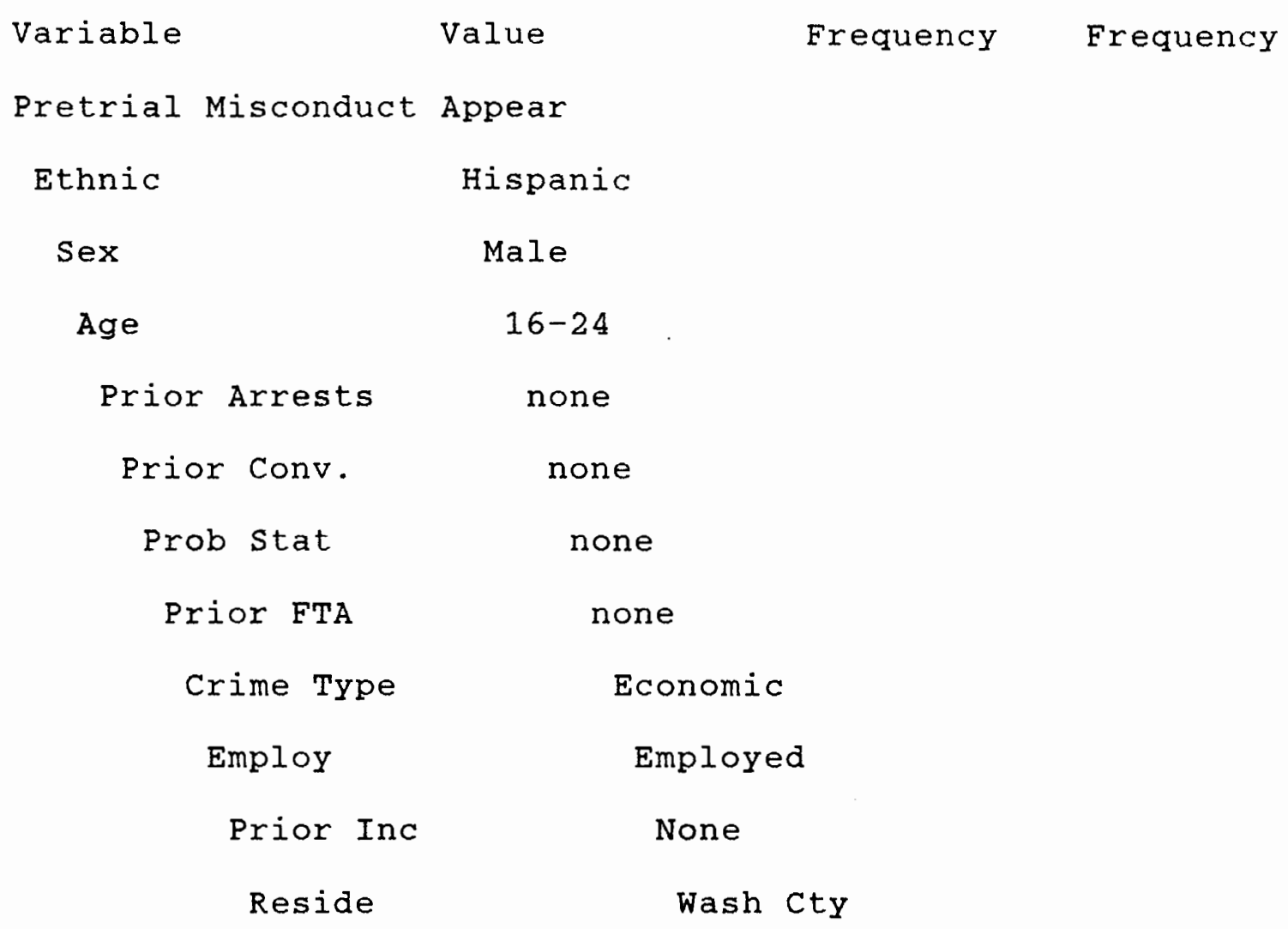

Figure 2. Multi-dimensional contingency table (partial display of log-linear output). 
z-scores for each parameter estimate are calculated, allowing for the test of the hypothesis that the parameter is equal to zero.

A step-wise procedure demonstrated by Fuchs and Flanagan (1980) will be utilized to develop the model.1 The goal of this technique is to develop a model with the lowest Chi-square ratio (the best fit) and the fewest effects. This procedure will entail:

1) an examination of the "independence model", that is the test of the null hypothesis that pretrial misconduct is independent across all levels of any of the independent variables. The independence model will yield an initial Likelihood Chi-Square ratio, with associated degrees of freedom and level of significance. This value of $\mathrm{L}^{2}$ will be the basis for comparing subsequent models. If the independence hypothesis is rejected, then some or all of the independent variables are related to the dependent variable.

2) Determine which independent variables are related to the dependent variable by examining the amount of variance that is "explained" by the interaction of an

1 This step-wise procedure has been used effectively in predicting the return to prison of adolescent males (Benda, 1989). 
independent variable with the dependent variable. Calculation of that variance is achieved by subtracting the value of the $\mathrm{L}^{2}$ for the cross-tabulation of the dependent variable with an independent variable from the $\mathrm{L}^{2}$ of the independence model. Independent variables that are strongly related to the dependent variable will "explain" larger amounts of variance than insignificant variables. Insignificant variables may be dropped from the analysis as they do not contribute to the model. The rejection region for the difference in the $L^{2}$ per degrees of freedom will be from 0 to 1.34 , as this is the maximum value of the chi-square (d.f. $=1, p<.25)$ to suggest acceptance of the null hypothesis. This procedure will be repeated until no difference in the $L^{2}$ is less than 1.34 .

3) The variable that accounted for the most variance, as measured by the largest reduction in the $L^{2}$ per d.f. will be "selected out". That is, the variance due to this variable will be subtracted from the cross-tabulation of the remaining independent variables with the dependent variables. The remaining value of the $L^{2}$ will represent the variance due to the remaining variables.

4) Determine the amount of variance that is due to each of the remaining independent variables as in step 2 . 
Variables that account for variance less than 1.34 may be removed from the analysis. This procedure will repeat until no decrease in the $L^{2}$ per d.f. is less than 1.34 .

5) The independent variable from step 4 that accounted for the largest amount of variance in cross-tabulation with the dependent variable will be "selected out" as in step 3 . The new value of the $L^{2}$ will be the $L^{2}$ of the cross-tabulation of the remaining variables minus the variance due to the variable "selected out" in step 3 minus the variance due to the variable "selected out" in step 5.

6) From the remaining independent variables, determine the amount of variance that is due to each. Remove insignificant variables as in steps 2 and 4 . If all the remaining variables account for variance larger than 1.34 , "select out" the variable that accounted for the largest amount of variance as in steps 3 and 5 . This procedure will be repeated until no further variables may be removed or "selected out" from the analysis. The variables that remain will compose the model.

ASSESSING THE IMPACT OF THE MODEL

From the resultant model, the log of the frequency of pretrial misconduct (Log $F_{p t m}$ ) may be calculated for each value of the variables contained in the model. For example, a model containing 4 variables, each having 2 values, would 
result in $16(2 \times 2 \times 2 \times 2)$ distinct combinations. These combinations of variable values may be interpreted as behavioral typologies.

$\log \left(F_{p t m}\right)=\mu+\lambda_{A}+\lambda_{B_{1}}+\lambda_{C_{i}}+\lambda_{A B_{i}}+\lambda_{A C_{i}}$

$+\mathrm{B}_{\mathrm{i}} \mathrm{C}_{1}$

where: $\mu=$ the grand mean

$\lambda_{A}=$ the log effect for pretrial misconduct

$\lambda x_{1}=$ the log effect of variable $x$ at level $i$.

Similarly, the log of the frequency of no pretrial

misconduct may be calculated. From these logs, the

probability of pretrial misconduct may be calculated:

Probability of Pretrial Misconduct (PTM) =

$\frac{\text { odds of PTM }}{1+\text { odds of PTM }}$

where:

odds of $P T M=\operatorname{Antilog}\left(\log \left(F_{p t m}\right)-\log \left(F_{n p t m}\right)\right)$.

As the parameter estimates sum to zero across all values of a given variable, the above equation may be written as:

$\mu+\lambda_{A}+\lambda_{B_{i}}+\lambda_{C_{i}}+\lambda_{A_{1}}+\lambda_{A B_{i}}+\lambda_{B_{i} C_{i}}$

$-\left(\mu-\lambda_{A}+\lambda_{B_{i}}+\lambda_{C_{i}}-\lambda_{A_{i}}-\lambda_{A_{B}}+\lambda_{B_{i} C_{i}}\right)$,

which will reduce to:

$2\left(\lambda_{A}+\lambda_{A B_{i}}+\lambda_{A_{1}}\right)$. 
The resultant probabilities will be calculated for all combinations of variables included in the model. Using these probabilities and their respective typologies, the observed incidence of pretrial misconduct will be calculated and compared with the expected rates.

The frequency of detained and released subjects will be calculated for each typology. As current policies assume that detained defendants pose a higher risk of pretrial misconduct, the frequency distribution would serve to demonstrate or refute that assertion.

\section{METHOD}

\section{Subjects}

Six hundred defendants arrested in washington County during the 2nd and 3rd quarter of 1991 served as subjects. The subjects were randomly selected from the records of the Washington County Jail using a random sample program on SPSS-X. All subjects had to meet one of the following criteria:

1) released on recognizance or on a surety (bail) bond; or

2) detained pending trial after being adjudged as unsuitable for pretrial release by the release officer or presiding judge. 
The subjects fell into two groups: detained and released (55 and 545 respectively). The detained subjects were analyzed separately. The released group was randomly divided into two groups: a construction sample ( $\mathrm{n}=395$ ), and a validation sample $(\mathrm{n}=150)$.

Materials

A data collection form (see Appendix D) was used to gather data from file materials. Data were collected from: jail records and included the arrest report and criminal history report; and, court records that indicated court appearances (Oregon Judicial Information Network, OJIN).

\section{Procedure}

The following data were collected from the records of each subject. For purposes of analysis, some of the data were coded. The data, their abbreviation, and their code (if necessary) are:

Name and Booking Number (for identification only)

Sex: male 0 ; female 1

Ethnic: Caucasian-non hispanic 1; African 2;

Caucasian-hispanic 3; Asian 4; Other 5 . 
Age: $(18-24) 1 ;(25-31) 2 ;(32-38) 3 ;(39-45) 4 ;$

$(46+) 5$.

Number of prior arrests (NPRA) 0 priors, 0; 1 prior, 1;

2-3 priors, 2; 4 and over, 3;

Number of prior convictions (NPRC) 0 priors, 0; 1 prior, 1;

2-3 priors, 2; 4 and over, 3;

Prior FTA convictions (PFTA): no 1; yes 2

Parole/probation status (PROB): no 1; yes 2

Type of Crime (CRTP): Crimes against persons 1; Economic

crimes 2; Drug crimes 3; crimes

against public morality 4; crimes

against public order 5; and,

miscellaneous crimes 6

Local Resident (RES): Washington County 1; Other Oregon

county 2; Out of state 3 .

Employment (EMPL): Unemployed 1; employed 2;

retired 3 ; student 4 ;

Prior Incarceration (PINC); yes 1; no 2

For all released subjects, court records were

monitored to determine if a subject engaged in pretrial

misconduct.

Pretrial misconduct (PTM): yes 0 ; no 1

Although data were collected for pretrial rearrest and 
failure to appear, no distinction between these two types of pretrial misconduct was made during the analysis. Pretrial misconduct was defined as: failure to appear for any court appearance, or arrest any time between the pretrial release and the disposition of that charge. 
CHAPTER VII

RESULTS

DESCRIPTIVE STATISTICS

The release rate (percentage of defendants in the sample who were released), detention rate (percentage of defendants who were denied release), pretrial misconduct rate (percentage of released defendants who either failed to appear or were rearrested while on pretrial release) were computed for the entire sample (see Table I). of the 600 subjects, $90.9 \%$ were granted some from of pretrial release. of those 545 released, $22.7 \%$ (124) engaged in some form of pretrial misconduct. In addition, means for proportions) were calculated across all independent variables (sex, ethnic, age, number of prior arrests, number of prior convictions, number of prior FTA convictions, crime type, residence, employment, and prior incarceration). These statistics were calculated 
TABLE I

RELEASE DETENTION AND

PRETRIAL MISCONDUCT RATES

Frequency Percentage

Detained

Released

Recognizance Releases

Bail Releases

Pretrial Misconduct

Rearrest

Fail to Appear

Total Sample
55

545

480

65

124

14

110

600
9.1

90.9

$88.1 *$

$11.9 *$

22.7 *

$2.5 *$

$20.2 *$

100

* percentages based on released subjects only 
seperately for: the total sample, detained defendants, defendants released with no pretrial misconduct, and defendants releassed with pretrial misconduct (see Table II).

DATA MODIFICATIONS

As a prelude to the Loglinear analysis, Pearson Chi-square statistics were computed for the crosstabulation of the dependent variable pretrial misconduct with each of the independent variables: sex, ethnic, age group, prior arrests, prior convictions, probation/parole status, prior FTA, crime type, employment, residence, and prior incarceration. The results indicated that the cell frequency of several variables in these crosstabulations was less than 5 . In order to minimize the incidence of sampling zeroes in the data analysis, five variables were modified.

Ethnic:

The construction sample included only 6 Asian (1 pretrial misconduct, 5 no pretrial misconduct) and 12 African (4 pretrial misconduct, 8 no pretrial misconduct) subjects. Crosstabulation of pretrial misconduct with Asian vs. African vs. white subjects yielded an insignificant chi-square of 1.95 
TABLE II

DISTRIBUTION OF THE INDEPENDENT VARIABLES

BY SELECTED GROUPS

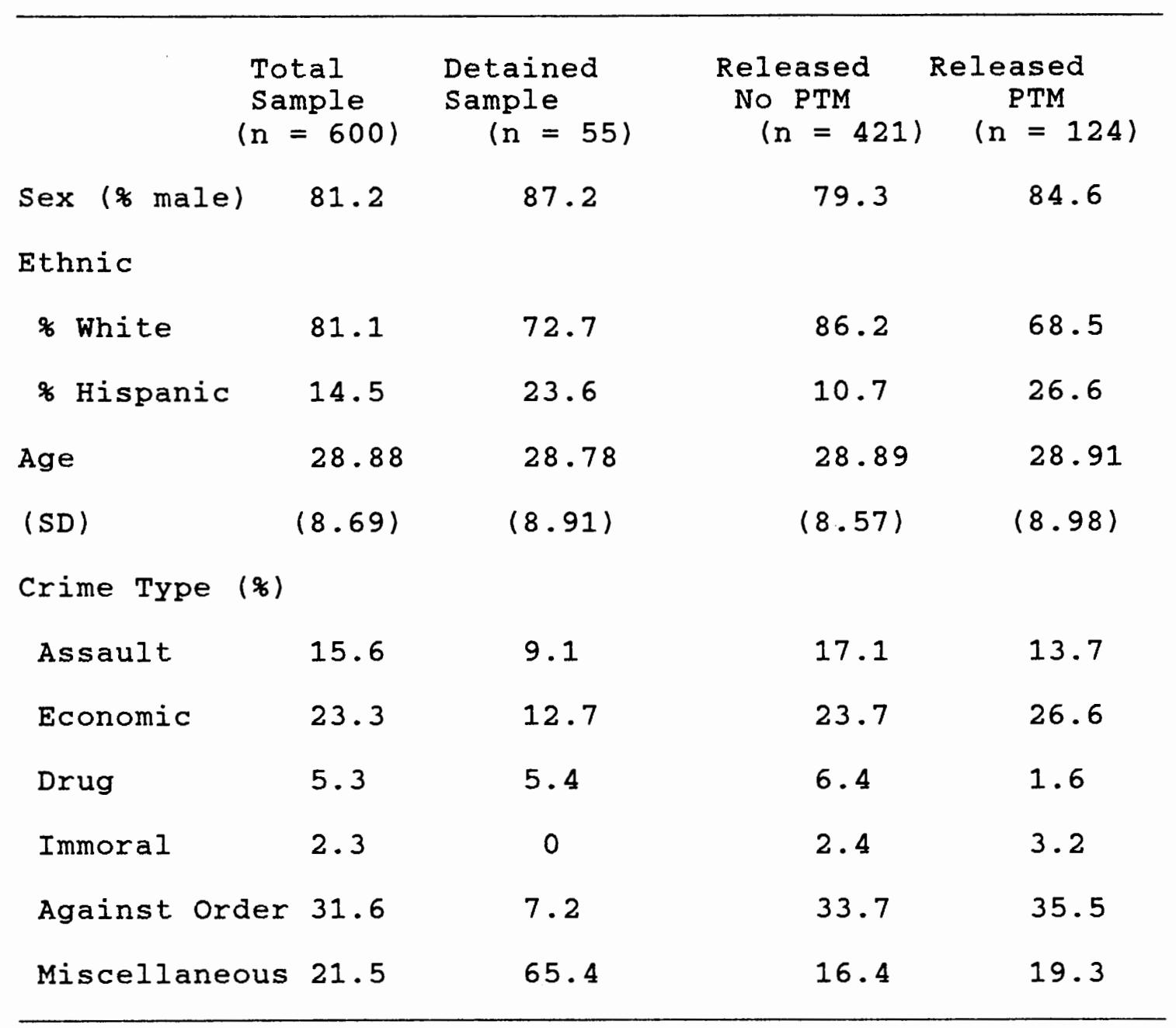


TABLE II

$$
\begin{gathered}
\text { DISTRIBUTION OF INDEPENDENT VARIABLES } \\
\text { BY SELECTED GROUPS } \\
\text { (continued) }
\end{gathered}
$$

\begin{tabular}{|c|c|c|c|c|}
\hline & $\begin{array}{l}\text { Total } \\
\text { Sample }\end{array}$ & Detained & $\begin{array}{l}\text { Released } \\
\text { No PTM }\end{array}$ & $\begin{array}{l}\text { Released } \\
\text { PTM }\end{array}$ \\
\hline & $=6001$ & $(n=55)$ & $(n=421)$ & $(n=124)$ \\
\hline $\begin{array}{l}\text { Probation } \\
\text { ( } \% \text { Yes) }\end{array}$ & 22 & 69 & 16 & 21 \\
\hline $\begin{array}{l}\text { Prior FTA } \\
\text { ( } \% \text { yes })\end{array}$ & 17 & 36.4 & 12.1 & 25 \\
\hline $\begin{array}{l}\text { Employment } \\
(\% \text { yes })\end{array}$ & 64 & 56.4 & 67.1 & 55.6 \\
\hline $\begin{array}{l}\text { Prior Incarc. } \\
\text { (\% yes) }\end{array}$ & 23 & 51 & 19.2 & 25 \\
\hline $\begin{array}{l}\text { Residence } \\
(\% \text { in Wash. }\end{array}$ & $\begin{array}{l}73.6 \\
y)\end{array}$ & 67.2 & 75 & 72 \\
\hline Prior Arrests & 2.42 & 6.13 & 2.11 & 2.47 \\
\hline (SD) & 3.93 & 5.82 & 3.69 & 3.85 \\
\hline Prior Conv. & 1.3 & 3.56 & .98 & 1.34 \\
\hline (SD) & 2.6 & 4.32 & 2.05 & 2.42 \\
\hline
\end{tabular}


(d.f. $=2, p>.25)$, indicating that the pattern of pretrial misconduct was similar for all three categories. The variable ethnic was modified to the dichotomy: Hispanic, non-Hispanic.

Age Group:

The age group of 46 and over consisted of only 19 subjects ( 4 pretrial misconduct, 15 no pretrial misconduct). The crosstabulation of pretrial misconduct with the age categories $39-45$ vs. 46 and over yielded an insignificant chi-square of .025 (d.f. $=1, \mathrm{p}>$.25). As the pattern of pretrial misconduct appeared to be the same for these two categories, they were combined in the analysis.

Crime Type:

The crime types of Drug and Against Public Morality contained only 18 ( 2 pretrial misconduct, 16 no pretrial misconduct) and 11 ( 2 pretrial misconduct, 9 no pretrial misconduct) subjects, respectively. The cross-tabulation of pretrial misconduct with drug vs. against public morality vs. with against public order was examined to determine if some or all of the crime type categories could be combined. The results yielded an insignificant chi-square of 1.375 (d.f. $=2, p>.25)$. For purposes of the loglinear 
analysis, the crime types of drug, against public morality, and against public order were combined.

Residence:

The out of state category contained only 19 subjects (5 pretrial misconduct, 14 no pretrial misconduct). A cross tabulation of pretrial misconduct with the out of state category vs. the other oregon county cattegory yielded an insignificant chi-square of .0195 $(d . f .=1, p>.25)$. As the pattern of pretrial misconduct appeared to be the same for both categories, the residence variable was modified into the dichotomy Washington County/ not Washington County .

Employment :

The categories of student ari retixed contained only 2 ( 1 pretrial misconduct, 1 no pretrial misconduct) and 7 (0 pretrial misconduct, 7 no pretrial misconduct) subjects respectively. A crosstabulation of pretrial misconduct with the employed vs. retired subjects yielded an insignificant chi-square of 1.009 (d.f. $=1$, p > .25). As these categories appeared to be independent with regard to pretrial misconduct, and since a chi-square could not be calculated for the 
student category, the employment variable was modified to the dichotomy: employed, unemployed; with the former categories of student and retired collapsed under the employed category.

The remainder of the variables had acceptable frequencies ( 2 ) across all levels in crosstabulation with the dependent variable pretrial misconduct (see Table III).

LOG-LINEAR ANALYSIS

The model of independence was examined which included: pretrial misconduct (dependent variable), age group, crime type, prior convictions, probation status, prior FTA, employment, residence, and prior incarceration. Three variables were excluded from this and further analysis: sex, ethnic, and prior arrests. Due to legal constraints, sex and ethnic were excluded. It should be noted however, that both variables had significant chi-squares during crosstabulation. Their significance will be discussed further in this chapter. Prior arrests was excluded due to its high correlation with prior convictions $\left(\mathrm{R}^{2}=.77\right)$, but more significantly, because of the amount of structural zeroes that this category would produce in the model. For 
TABLE III

CROSSTABULATION OF THE INDEPENDENT VARIABLES BY THE DEPENDENT VARIABLE PRETRIAL MISCONDUCT

\begin{tabular}{lccc}
\hline Variable & Chi-Square & DF & p \\
Sex & 3.47 & 1 & .06 \\
Ethnic & 28.48 & 1 & .000 \\
Age Group & 5.26 & 3 & .15 \\
Prior Arrests & 4.39 & 3 & .22 \\
Prior Convictions & 4.75 & 3 & .19 \\
Probation Status & 1.02 & 1 & .31 \\
Prior FTA & 15.44 & 1 & .00009 \\
Crime Type & .6 & 3 & .89 \\
Employment & 6.6 & 1 & .01 \\
Residence & .407 & 1 & .52 \\
Prior Incarceration & 2.69 & 1 & .1 \\
\hline
\end{tabular}


example, there will be no subjects in the cell " 0 prior arrests and (2-3) prior convictions".

The test of the independence model yielded a $L^{2}$ of $230.78(\mathrm{~d} . \mathrm{f} .=188, p=.018)$ suggesting that the null hypothesis, that pretrial misconduct is independent with regard to the independent variables, should be rejected. The significance suggests that the pattern of pretrial misconduct varies widely across the independent variables, and that the independence model does not fit the data well. By examining the effect of each variable in the model, the amount of variance that each independent variable accounts for in pretrial misconduct may be calculated. This analysis will allow for the identification of those variables that "explain" the most and the least variance. Insignificant variables may be removed as the variance they account for is minimal. Conversely, significant variables will be retained in the model.

In step 1, the variable Crime Type (CRIMTP) accounted for the smallest reduction in the $L^{2}$ per d.f. (.196). The crosstabulation with pretrial misconduct indicated that the pattern of pretrial misconduct was the same across crime types. Crime type was dropped from the analysis and the cycle was repeated. The results also indicated that the variable prior FTA (PFTA) accounted for the largest reduction in the $L^{2}$ per d.f. (13.66) (see Table IV). In step 2, the new independence model consisting of 
TABLE IV

LOGLINEAR ANALYSIS OF PRETRIAL MISCONDUCT

IN Step 1

\begin{tabular}{lccccc}
\hline & & & \multicolumn{3}{c}{ Difference } \\
ModeI & $\mathrm{L}^{2}$ & $\mathrm{~d} . \mathrm{f}$. & $\mathrm{p}$ & \multicolumn{2}{c}{ in $\mathrm{L}^{2}$ per d.f. } \\
Independence $*$ & 230.74 & 188 & .018 & \\
RESIDE & 230.34 & 187 & .017 & .4 \\
CRIMTP & 230.15 & 185 & .013 & .196 \\
PRIORIN & 228.16 & 187 & .021 & 2.58 \\
PRCONV & 226.22 & 185 & .021 & 1.51 \\
AGE & 224.90 & 185 & .024 & 1.94 \\
EMPLOY & 224.29 & 187 & .032 & 6.45 \\
PFTA & 217.08 & 187 & .065 & 13.66 \\
PROBST & 229.76 & 187 & .018 & .98 \\
\hline
\end{tabular}

* including the variables: Residence, Crime Type, Prior Incarceration, Prior Convictions, Age, Employment, Prior FTA, Probation/Parole status. 
TABLE V

LOGLINEAR ANALYSIS OF PRETRIAL MISCONDUCT

IN Step 2

\begin{tabular}{|c|c|c|c|c|}
\hline \multirow[b]{2}{*}{ Model } & \multirow[b]{2}{*}{$\mathrm{L}^{2}$} & \multirow[b]{2}{*}{ d.f. } & \multicolumn{2}{|r|}{ Difference } \\
\hline & & & $\cdot p$ & in $L^{2}$ per $d . f$ \\
\hline Independence & 173.49 & 127 & .004 & \\
\hline RESIDE & 173.09 & 126 & .003 & .4 \\
\hline PROBST & 172.11 & 126 & .005 & .98 \\
\hline PRIORIN & 170.91 & 126 & .005 & 2.58 \\
\hline PRCONV & 168.96 & 124 & .005 & 1.51 \\
\hline EMPLOY & 167.04 & 126 & .008 & 6.45 \\
\hline$A G E$ & 167.65 & 124 & .006 & 1.94 \\
\hline PFTA & 159.83 & 124 & .022 & 13.66 \\
\hline
\end{tabular}

* including the variables: Residence, Probation/Parole Status, Prior Incarceration, Prior Convictions, Employment, Age, Prior FTA. 
the variables: Reside, Prior Incarceration, Prior Convictions, Age, Employment, Prior FTA, and Probation/Parole status, yielded a $L^{2}$ of 173.49 (d.f. = 127, $p=.004$ ). The variable Prior FTA again accounted for the largest reduction in the $L^{2}(13.66)$. The variable Residence resulted in the smallest reduction (.4). As the crosstabulation indicated that residence is independent with regard to pretrial misconduct, it was dropped from the analysis and the cycle was repeated (see Table V).

The new independence model in step 3, consisting of the variables: Prior Incarceration, Prior Convictions, Age, Employment, Prior FTA, and Probation/Parole status, yielded a $L^{2}$ of 143.05 (d.f. $\left.=99, p=.003\right)$. The variable Prior FTA resulted in the largest reduction in the $L^{2}(13.66)$. The variable probation-parole status resulted in the smallest reduction (.98). As the crosstabulation indicated that probation/parole status has no effect on pretrial misconduct, it was dropped from the analysis and the cycle was repeated (see Table VI).

In step 4, the new independence model, consisting of the variables: Prior Incarceration, Prior Convictions, Age, Employment, and Prior FTA, was tested. Because the loglinear analysis indicated that these variables all accounted for reductions in the $L^{2}$ greater than 1.34 
TABLE VI

LOGLINEAR ANALYSIS OF PRETRIAL MISCONDUCT

IN step 3

\begin{tabular}{|c|c|c|c|c|}
\hline \multirow[b]{2}{*}{ Model } & \multirow[b]{2}{*}{$\mathrm{L}^{2}$} & \multicolumn{3}{|r|}{ Difference } \\
\hline & & $d . f$ & $\mathrm{p}$ & in $L$ per $d . f$ \\
\hline Independence * & * 143.05 & 99 & .003 & \\
\hline PROBST & 142.07 & 98 & .002 & .98 \\
\hline PRIORIN & 140.47 & 98 & .003 & 2.58 \\
\hline PRCONV & 138.53 & 96 & .004 & 1.5 \\
\hline$A G E$ & 137.21 & 96 & .004 & 1.94 \\
\hline EMPLOY & 136.6 & 98 & .006 & 6.45 \\
\hline PFTA & 129.39 & 98 & .003 & 13.66 \\
\hline
\end{tabular}

* including the variables: Probation/Parole Status, Prior Incarceration, Prior Convictions, Age, Employment, Prior FTA 
TABLE VII

LOGLINEAR ANALYSIS OF PRETRIAL MISCONDUCT

IN Step 4

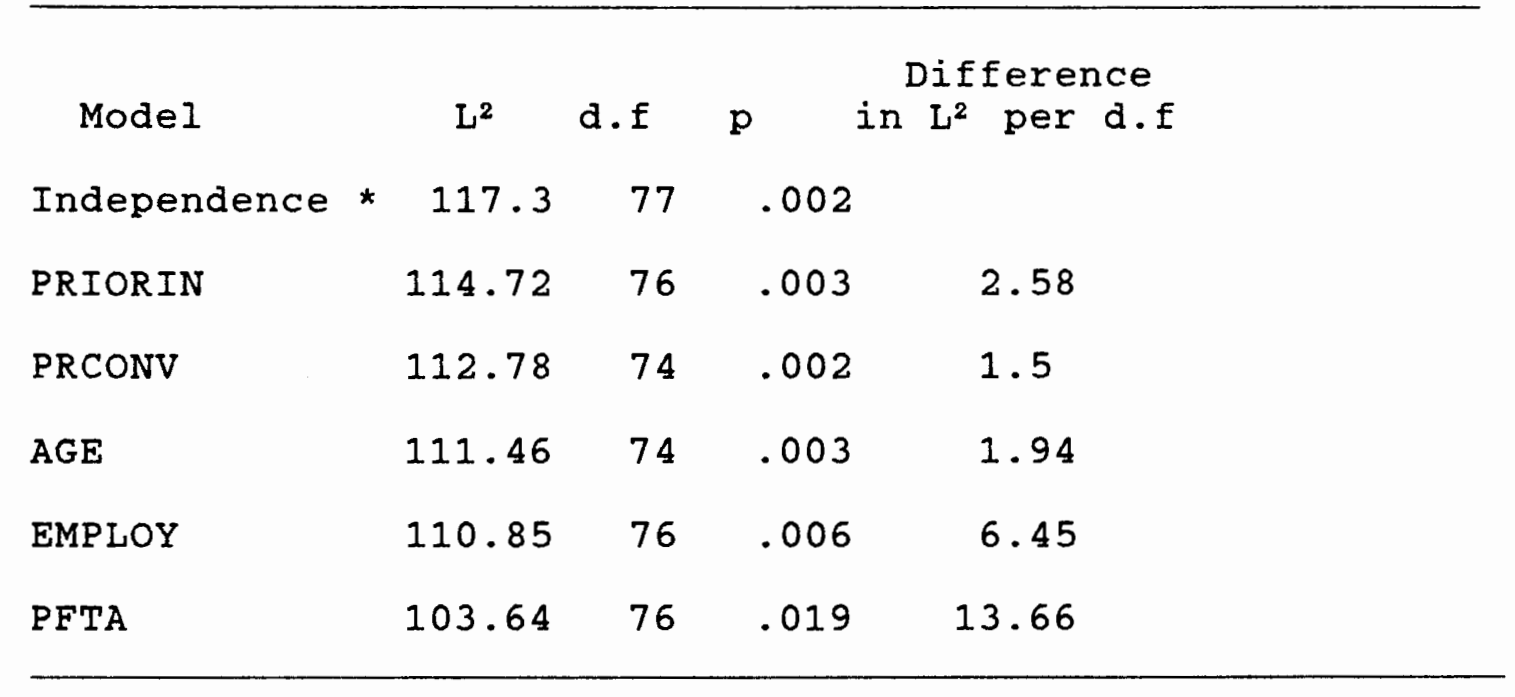

* including the variables: Prior Incarceration, Prior Convictions, Age, Employment, Prior FTA 
(the critical region for $\mathrm{X}^{2}, \mathrm{df}=1, \mathrm{p}<.25$ ), no more variables were subject to backward elimination at that time (see Table VII). The next step identified the variable that provided the greatest reduction in the $\mathrm{L}^{2}$ per d.f., that is, the variable that "explained" the most variance. The variable prior FTA consistently provided the greatest reduction in the $L^{2}$ per $d . f .$, and was the first variable "selected out" for the predictive model. The selection of this variable is analogous to step-wise model building in multiple linear regression, where the "best" predictor is selected first. The next step of the analysis was to examine the variance that is due to the remaining variables. The basis for comparison is the $\mathrm{L}^{2}$ for the crosstabulation of the remaining independent variables with the dependent variable minus the $L^{2}$ of the simple crosstabulation of Prior FTA with pretrial misconduct.

In step 5, the tentative model, consisting of the variables: Employ, Prior Incarceration, Prior Convictions, Prior FTA, and Age - the $\mathrm{L}^{2}$ of Prior FTA, yielded a $\mathrm{L}^{2}$ of 103.64 (d.f. $=76, p=.019$. The significance level suggests that the model fit is improving. The variable Prior Incarceration resulted in the smallest reduction in the $L^{2}(.08)$, while the variable Employment resulted in the largest reduction (6.09). As the variable prior 
TABLE VIII

LOGLINEAR ANALYSIS OF PRETRIAL MISCONDUCT

IN Step 5

\begin{tabular}{|c|c|c|c|c|}
\hline \multirow[b]{2}{*}{ Model } & \multirow[b]{2}{*}{$\mathrm{L}^{2}$} & \multirow[b]{2}{*}{. $f$. } & \multicolumn{2}{|c|}{ Difference } \\
\hline & & & in & $\mathrm{L}^{2}$ per $\mathrm{d} . \mathrm{f}$. \\
\hline PFTA & 103.64 & 76 & .019 & \\
\hline PFTA EMPLOY & 97.55 & 75 & .041 & 6.09 \\
\hline PFTA PRIORIN & 103.56 & 75 & .016 & .08 \\
\hline PFTA PRCONV & 101.14 & 73 & .016 & .83 \\
\hline PFTA AGE & 97.05 & 73 & .031 & 2.2 \\
\hline
\end{tabular}


incarceration was unable to contribute to the significance of the model, it was dropped from the analysis and the cycle was repeated (see Table VIII).

In step 6 , the tentative model consisting of the variables: Employ, Prior Convictions, Prior FTA, and Age minus the $\mathrm{L}^{2}$ of Prior FTA yielded a $\mathrm{L}^{2}$ of 77.73 (/d.f. $=53, p=.022)$. The variable Employment resulted in the largest reduction in the $L^{2}$ per degress of freedom (7.10). In addition, the analysis indicated that the variable Prior Convictions resulted in the smallest decrease in the $L^{2}(.875)$. The variable Employment was "selected out" and the variable prior convictions was dropped from the analysis (see Table IX).

In step 7 , the tentative model consisting of the variables Prior FTA, Employment, and Age minus the $\mathrm{L}^{2}$ 's due to Employment and Prior FTA yielded a $\mathrm{L}^{2}$ of 17.74 (d.f. $=13, p=.044)$. The variable Age resulted in a reduction of the $L^{2}$ greater than 1.34 and was "selected out" for the predictive model (see Table $\mathrm{X}$ ).

In step 8 , the model consisting of the variables prior FTA, Employment, and Age minus the $L^{2}$ 's due to each of those variables resulted in an $L^{2}$ of 11.23 (d.f. $=10, p$ $=.339$. The significance level indicates that the model is good fit to the data (see Table XI). model resulted in a smaller $L^{2}$ or a better fit (see Table 10). 
TABLE IX

LOGLINEAR ANALYSIS OF THE TENTATIVE MODEL OF PRETRIAL MISCONDUCT IN STEP 6

\begin{tabular}{lcccc}
\multicolumn{1}{c}{ Model } & \multicolumn{3}{c}{ L } & \multicolumn{3}{c}{ Difference } \\
PFTA & 77.73 & 53 & .022 & 13.66 \\
PFTA EMPLOY & 70.63 & 52 & .044 & 7.10 \\
PFTA PRCONV & 74.23 & 50 & .015 & .875 \\
PFTA AGE & 70.14 & 50 & .032 & 1.89 \\
\hline
\end{tabular}


TABLE X

LOGLINEAR ANALYSIS FOR THE TENTATIVE MODEL OF PRETRIAL MISCONDUCT IN STEP 7

\begin{tabular}{lcccc}
\hline & & & \multicolumn{2}{c}{ Difference } \\
Model & $\mathrm{L}^{2}$ & d.f. & $\mathrm{p}$ & in $\mathrm{L}^{2}$ per d.f. \\
PFTA & 23.83 & 14 & .019 & 13.66 \\
PFTA AGE & 17.24 & 12 & .031 & 2.19 \\
PFTA EMPLOY & 17.74 & 13 & .044 & 3.04 \\
\hline
\end{tabular}

TABLE XI

LOGLINEAR ANALYSIS FOR THE TENTATIVE MODEL OF PRETRIAL MISCONDUCT IN STEP 8

\begin{tabular}{crrrr} 
& & & \multicolumn{2}{c}{ Difference } \\
Model & $\mathrm{L}^{2}$ & $\mathrm{~d} . \mathrm{f}$. & $\mathrm{p}$. & \multicolumn{2}{c}{ in $\mathrm{L}^{2}$ per d.f. } \\
Independence & 37.49 & 15 & .001 & \\
PFTA EMPLOY AGE & 11.23 & 10 & .339 & 2.17 \\
\hline
\end{tabular}


In the interest of parsimony, no further analysis was conducted. The remaining variance may have been accounted for through higher order interactions with the variables in the model; however, the interpretive value of the model may not have been improved.

The results of the Loglinear Analysis revealed a predictive model of pretrial misconduct containing the effects: Pretrial Misconduct, Prior FTA, Employment, and Age. Loglinear calculated regression like coefficients for the variables included in the model. As discussed on pages 38-40, these parameter estimates are the variables' effect on the grand mean of the cell frequencies. These coefficients will be used to calculate the probability of pretrial misconduct. The parameter estimates indicate that most of the coefficients are greater than zero at the .05 level, the exception being the following values of the age variable: 18-24, 25-31, and 39 and over (see Table XII). Using the formulas discussed on pages 41 and 42 , the probability of pretrial misconduct was calculated for the 16 constellations of traits, found by combining the levels of PFTA ( 2 values), Age ( 4 values), and Employment (2 values). Table 11 lists the parameter estimates for the variables in the model. The constant is the log effect for pretrial misconduct, which is analogous to the constant in 
TABLE XII

PARAMETER ESTIMATES FOR THE SELECTED MODEL (DERIVED FROM THE LOGLINEAR ANALYSIS)

\begin{tabular}{lcccc}
\hline Parameter & Estimate & Z-Value & Parameter $x 2$ & Antilog \\
Constant & -.4555 & -5.209 & -.911 & .402 \\
& & & & \\
Prior FTA & -.298 & -3.78 & -.596 & .55 \\
(Prior FTA) & .298 & & .596 & 1.81 \\
Age 16-24 & .144 & 1.41 & .288 & 1.33 \\
$\quad 25-31$ & .128 & 1.23 & .256 & 1.29 \\
32-38 & -.346 & -2.225 & -.692 & .86 \\
(39 and over) & -.074 & & -.148 & 1.36 \\
Not Employed & .155 & 2.459 & .31 & .73 \\
(Employed) & -.155 & & -.31 & \\
\hline
\end{tabular}

Values in parentheses are the difference between 0 and the sum of the coefficients in single parameter. 
a regression equation. The values in parentheses are the difference between zero and the sum of the known parameter estimates, as these will sum to zero across all values of a variable.

\section{Constructing the Model}

The frequency of subjects from the construction sample in each constellation of traits was calculated along with the percentage of error (predicted percentage - observed percentage). The expected probabilities of pretrial misconduct ranged from $57 \%$ to $8 \%$. The results indicated that 8 typologies had frequencies less than 10, with one typology containing one subject. In typologies with small frequencies, each subject accounts for a larger percentage. Wider error estimates would be expected. As expected, the error estimates ranged from $67 \%$ to 0 and averaged 13.5 (see Table XIII). The biggest error was found in the typology with only one subject. The average of the error estimates in typologies with frequencies greater than 10 was 5.6 (SD $=4.5, \mathrm{n}=81$.

\section{Validating the Model}

The frequency of subjects from the validation sample in each of the typologies was calculated along with a 
TABLE XIII

PREDICTED AND OBSERVED RATES OF PRETRIAL MISCONDUCT IN THE 16 TYPOLOGIES FROM THE CONSTRUCTION SAMPLE

\begin{tabular}{lllcclc}
\hline \multicolumn{2}{c}{ Typology } & & Predicted & Observed & n & Error \\
PFTA & Age & Employ & $(\%)$ & $(\%)$ & & \\
1) yes & $18-24$ & no & 57 & 50 & 6 & 7 \\
2) yes & $25-31$ & no & 56 & 50 & 2 & 6 \\
3) yes & $39+$ & yes & 51 & 67 & 3 & 16 \\
4) yes & $18-24$ & yes & 48 & 33 & 9 & 15 \\
5) yes & $39+$ & no & 46 & 50 & 2 & 4 \\
6) yes & $25-31$ & yes & 41 & 37 & 16 & 4 \\
7) no & $39+$ & no & 37 & 71 & 7 & 34 \\
8) yes & $32-38$ & no & 33 & 100 & 1 & 67 \\
9) no & $18-24$ & no & 29 & 37 & 49 & 8 \\
10) no & $25-31$ & no & 28 & 28 & 35 & 0 \\
11) no & $39+$ & yes & 24 & 10 & 29 & 14 \\
12) yes & $32-38$ & yes & 21 & 43 & 7 & 22 \\
13) no & $18-24$ & yes & 18 & 16 & 80 & 2 \\
14) no & $25-31$ & yes & 17 & 20 & 75 & 3 \\
15) no & $32-38$ & no & 13 & 4 & 22 & 9 \\
16) no & $32-38$ & yes & 8 & 35 & 5 \\
\hline
\end{tabular}


in each of the typologies was calculated along with a proportionate reduction in error measure (PRE), where: $P R E=E_{c s}-E_{v s}$

Ecs. $E_{c s}=$ the error estimate of the construction sample; and, $E_{v s}=$ the error estimate of the validation sample.

The results indicted that the low frequencies (less than 10) were observed in 10 of 16 typologies. The mean of the PRE was 1.15 ( $S D=1.19$ ) indicating that shrinkage was minimal. The small frequencies in the typologies mitigate this finding however (see Table XIV).

A spearman Rank order test was conducted comparing the observed and expected rates of pretrial misconduct in the construction and validation samples. The results yielded Rank order coefficients of .7 for the construction sample and .45 for the construction sample. As the ultimate value of the predictive model will be to rank subjects as to their predicted risk of pretrial misconduct, the rank order test provides an estimate of that ability.

Calculating the errors of measurement using the predicted and observed frequencies indicated that 22 errors (5.5\%) were present in the construction sample. Of these 22 errors, $11(2.78 \%)$ represented underestimations of pretrial misconduct. From the validation sample, 14 errors (9.3\%) 
TABLE XIV

PREDICTED AND OBSERVED RATES OF PRETRIAL MISCONDUCT FOR THE CONSTRUCTION AND VALIDATION SAMPLES

\begin{tabular}{lrrrrrr}
\hline Type & Predicted & $\begin{array}{c}\text { Observed } \\
\text { Construction }\end{array}$ & $\mathrm{n}$ & $\begin{array}{c}\text { Observed } \\
\text { Validation }\end{array}$ & $\mathrm{n}$ & PRE \\
1) & 57 & 50 & 6 & 50 & 4 & 0 \\
2) & 56 & 50 & 10 & 75 & 4 & 1.2 \\
$3)$ & 51 & 67 & 3 & 100 & 2 & 3.0 \\
4) & 48 & 33 & 9 & 0 & 2 & 2.5 \\
$5)$ & 46 & 50 & 2 & 50 & 4 & 0 \\
$6)$ & 41 & 37 & 16 & 20 & 5 & 4.2 \\
$7)$ & 37 & 71 & 7 & 25 & 4 & .65 \\
$8)$ & 33 & 100 & 1 & 0 & 2 & 1.49 \\
$9)$ & 29 & 37 & 49 & 31 & 16 & .75 \\
$10)$ & 28 & 28 & 35 & 0 & 9 & 0 \\
$11)$ & 24 & 10 & 29 & 38 & 13 & 1 \\
$12)$ & 21 & 43 & 7 & 33 & 3 & .45 \\
$13)$ & 18 & 16 & 80 & 19 & 26 & .5 \\
$14)$ & 17 & 20 & 75 & 16 & 30 & .66 \\
$15)$ & 13 & 4 & 22 & 20 & 10 & .22 \\
$16)$ & 8 & 3 & 35 & 22 & 18 & 1.8 \\
\hline
\end{tabular}


PREDICTED AND OBSERVED FREQUENCIES OF PRETRIAL MISCONDUCT FROM THE CONSTRUCTION AND VALIDATION SAMPLES BY TYPOLOGY

\section{Construction sample | Validation Sample}

Typology Predicted Observed Error 1 Predicted Observed Error

1)

2)

3)

4)

5)

6)

7)

8)

9)

10)

11)

12)

13)

14)

15)

16)
3

1

2

4

1

7

3

0

14

10

7

1

14

13

3

3
3

1

2

3

1

6

5

1

18

10

3

3

13

15

1

1

1

2

2

1

1

2

2

1

1

5

3

3

1

5

5

1

1
2

0

$-1$

$-1$

1

0

1

0

1

0

3

0

$-2$

5

1

0

5

0

5

0

$2 \quad-1$

$4 \quad-3$ 
were observed, with 8 errors (5.3\%) representing underestimations of pretrial misconduct. The difference between the proportion in errors from the construction and validation samples was not significant at the .05 level (see Table XV). Spearman Rank Order tests conducted on the freqencies yielded coefficients of .847 for the construction sample and .626 for the validation sample. The results suggest that the model does provide an accurate typology of high-low risk defendants, with regard to pretrial misconduct.

The Erequency of the detained subjects in each of the typologies was calculated and compared with the frequencies of the combined released samples (see Table XVI). A chi-square of $36.6(\mathrm{~d} . \mathrm{f} .=15, \mathrm{p}<.005)$ indicates that the categories are not independent. In addition, the distribution of detained and released subjects across the typologies indicated that $31 \%$ of the detained subjects were in the high-risk typologies (\#'s $1-8$ ) as compared to $7.8 \%$ of the released subjects. These results suggest that detained and released subjects do differ by the typologies suggested by the model, and that detained subjects represented a higher risk of pretrial misconduct than the released subjects. 
TABLE XVI

\begin{abstract}
FREQUENCY OF DETAINED AND RELEASED SUBJECTS
ACROSS THE 16 TYPOLOGIES
\end{abstract}

\section{Type}

1)

2)

3)

4)

5)

6)

7)

8)

9)

10)

11)

12)

13)

14)

15)

16)
Detained

2

2

0

4

1

4

0

4

6

3

2

2

6

8

6

4
Released

10

14

5

11

3

21

11

3

65

44

42

10

106

105

32

53 
CHAPTER VIII

\section{DISCUSSION}

THE PREDICTIVE MODEL

The predictive model was successful in identifying high and low risk typologies for pretrial misconduct. Small frequencies in several typologies limited a more accurate assessment of the model's validity. Though the model contained only three effects, prior FTA, age, and employment, it has interpretable value. Further, the effects that the model did not include require some examination as they appear to contradict popular notions of both criminality and pretrial misconduct.

The typologies derived from the model illustrate the interactions of Prior FTA, Employment, and Age on pretrial misconduct. The trend evidenced through typologies $1-6$ (refer to Table XIII) is the significance of Prior FTA in the higher risk typologies. This is especially true for younger offenders aged 18 - 31 years. In typologies 7 
- 10, unemployment appears to be the dominant theme. In these typologies, the probabilities of pretrial misconduct range from $28 \%$ to $37 \%$ and include all the age groups. Prior FTA is a secondary factor evident in these typologies. In typologies 11 - 16, no Prior FTA and being employed are the dominant effects, with tye probability of pretrial misconduct ranging from $8 \%$ to $24 \%$.

These trends suggest that stabilizing or conforming factors, such as employment or no prior FTA's are associated with the lack of pretrial misconduct. Conversely, destabilizing factors such as unemployment and prior FTA's are associated with pretrial misconduct. The typologies suggest that the probability of pretrial misconduct increases with the presence of these destabilizing factors.

The typologies derived from the model do not reject the assumption by sturz (1962), regarding how ties to the community (Employment, Prior Record) may be significant in the incidence of pretrial misconduct.

Prior FTA was the most significant variable in the predictive model. The finding that this variable is significant in predicting pretrial misconduct affirms the work of Toborg (1989). Prior FTA's were present in 7 of the top 8 typologies. Initially, it would appear that the 
implication is that past behavior is the best predictor of future behavior. However, the presence of a prior FTA also indicates that there was prior contact with the criminal justice system. The amount of that contact, as measured by prior arrests, did not vary significantly between subjects who engaged in pretrial misconduct and those that did not. However, prior convictions did vary significantly (p< .05). It would appear that the quantity of prior contact with the criminal justice system is not as important, in terms of pretrial misconduct, as the quality of those contacts. This quality, though inferred to be arrests that result in convictions, may include a variety of factors not assessed by this study, such as the psychological impact of arrest and conviction. The results do suggest that while prior convictions have an impact on pretrial misconduct, it is not a desirable one.

Employment was the second most significant factor in the model. Its significance is mitigated by interactions with the other elements of the model. This is evidenced by the fact that the value "no employment" is present in only 5 of the top 8 typologies. Unemployment for younger offenders (18-31 years) was more significant in the incidence of pretrial misconduct than for older offenders. Surprisingly, employment status was positively related to 
pretrial misconduct for the age group "39 and over", and appeared to have only a random influence on the age group "32-38". The lack of a definitive trend as to the impact of employment status on pretrial misconduct may be due to the robust interpretive nature of the variable. Employment is confounded with issues of full or part time work, unsatisfying or satisfying employment, and competitive or subsistence wages. The values of full and part time employment were intended to be gathered by this author. However, that type of information is unavailable except through an interview with the subject. The lack of a definitive trend may also be due to the small sample sizes in the categories of student and retired.

Age was the final effect in the model. Younger (18-31) offenders accounted for 3 of the top 4 typologies. While questions of the appropriateness of age as a selection criterion have been raised (Toborg, 1989), its significance should not go unexamined. As previously mentioned, younger offenders account for the largest percentage of all crimes (42\%) (U.S. Department of Justice, 1988). In this study, the mean age was $28.88(\mathrm{SD}=8.69, \mathrm{n}$ $=600)$, and did not vary significantly between the detained, released with pretrial misconduct, and released without pretrial misconduct groups. Sex and ethnic 
differences moderated the relationship between age and pretrial misconduct, e.g., women offenders who had a lower rate of pretrial misconduct than men (15.1\% vs. 21.5\%) were slightly older, and hispanic offenders, who had a higher rate of pretrial misconduct than non-hispanics (44.6\% vs. 19.2\%) were slightly younger. These differences suggest that the impact of age on pretrial misconduct may lie in interaction with other variables in the model, or in other constructs that were not examined. The data suggest that younger offenders (18-31 years) with prior contact with the criminal justict sitem (specifically prior FTA's) are more likely to engage in pretrial misconduct than younger offenders with no such history. In addition, these young offenders with prior contact with the criminal justice system, are even more likely to engage in pretrial misconduct if they are currently unemployed.

Certainly within the variable of age is the construct of maturity or stability. Although Hogan \& Jones (1983) had observed higher rates of impulsiveness in younger, non-violent offenders, no clear trend is evident from the results of this study. The hypothesis that younger offenders would show higher rates of pretrial misconduct is supported by the data. 
The model may be used by jail personnel or Release Assistance officers to identify high-low risk (of pretrial misconduct) offenders. At the time of arrest, a defendant could be ranked into one of the 16 typologies. Data on the pretrial behavior of these defenants would serve to field test the model. As these individuals may find the model too parsimonious, they may employ additional factors in rendering release decisions. Regardless of the additional factors that may be used, field testing of the model will allow for a more definitive evaluation of its validity. In addition, the data base generated by this field test would provide a valuable resource for further examination of pretrial misconduct.

SEX AND ETHNIC

The exclusion of sex and ethnic from the predictive model was appropriate for legal reasons, as neither variable should be used as a selection criterion. However, the fact that both variables yielded significant chi-squares during cross-tabulation with the dependent variable demands some examination. It would appear that criminality in women differs in some way from criminality in men. In this study, women offenders were only slightly older ( 29.27 vs. 28.79 years), and were less likely to have 
been on probation or parole than men (17\% vs. $24 \%$ ). In addition, women offenders had both fewer prior arrests and convictions than men ( 1.77 vs. 2.7 and .875 vs. 1.38 respectively). Women offenders were also more likely to be unemployed than males $(50 \%$ unemployed women vs. $34 \%$ unemployed males). More than a third (36.6\%) of the women offenders engaged in economic crimes as compared to $23.3 \%$ for the entire sample.

Though no clear profile emerges, the results suggest that women offenders may be motivated by economic factors, as opposed to engaging in assaultive behavior. The fact that more women were unemployed and slightly older, and had fewer previous contacts with the criminal justice system than men, supports this assertion as the instability associated with economic distress may elicit impulsive behaviors. The relationship between crime and economic distress and income inequality has been established (BIau \& Blau, 1982; Barley, 1984). In addition, state and federal programs designed to establish economic parity have been shown to reduce crime rates (DeFronzo, 1983).

The ethnic variable was included in the initial loglinear analysis. During these analyses, it was evident that ethnic consistently provided the greatest reduction 
in the $\mathrm{L}^{2}$. However, the variable was dropped from the analysis as it was not appropriate to be included. Hispanics are of significance in Washington County as they are the dominant minority, representing $4.6 \%$ of the population. Hispanics are also the dominant minority in the county's jail, comprising $14.5 \%$ of the total sample and $23.6 \%$ of the detained subjects. Hispanic offenders tended to be younger than non-hispanics (26.7 vs. 28.89), and were more likely to be unemployed (50\% vs $33 \%$ ). Hispanics also tended to engage in crimes against public order (predominantly Driving Under the Influence of Intoxicants) more often than non-hispanics (33\% vs. 30\%). Hispanics were also much more likely to engage in pretrial misconduct than non-hispanics $(37.9 \%$ vs. $17.7 \%)$, a result that was also found by Toborg (1981).

This high rate of pretrial misconduct is only partially explained by the model, i.e., that younger, unemployed offenders may be more likely to engage in pretrial misconduct. The model does not address the issue that some of this employment may be at sub-minimum wage, or that the subject lives in sub-standard housing, or that the subject may have no grasp of the language or culture, let alone the legal system. Further, it is reasonable to assume 
that some percentage of hispanic offenders do not have appropriate legal status. Thus, an appearance in court or a conviction may mean deportation.

The Eact that pretrial misconduct did vary by ethnicity is significant. What factors contribute to that significance is unclear. The issue is confounded by the language problem, specifically, what percentage of hispanics are functionally literate in English. Conversely, to what degree does the legal system ensure that non-English speakers understand oral or written communications? It is also confounded by the economic problem, specifically, what percentage of hispanic offenders are working at sub-minimum wage jobs, or do not have appropriate legal status in this country?

The exclusion of the variable crime type erodes at popular notions of both criminality and pretrial misconduct. Crime type is a primary discriminating criterion in pretrial release. In washington county for example, assaultive offenders have been recognized as more deserving of jail space than other offenders (Cargill, 1986). Despite this recognition, the results of this study did not show that assaultive offenders poseed greater risks of pretrial misconduct than any other type of offender. Further, assaultive offenders comprised 
$15.6 \%$ of the total sample, but only accounted for $9.1 \%$ of the detained population. The lack of a clear trend with regard to crime type suggests that pretrial misconduct may be the product of random situational or other factors. Gibbon's (1983) notion of "mundane" crime, or crimes that may result from random situational factors, may well describe pretrial misconduct. Toborg (1981) has suggested that the low incidence of pretrial misconduct $(22.2 \%$ in this study) may be indicative of its randomness.

Nevertheless, the crime taxonomy utilized in this study may provide homogenous crime groups that the felony/misdemeanor dichotomy can not. However, pretrial misconduct did not appear to vary by crime type. The hypothesis that offenders charged with economic crimes would pose greater risks of pretrial misconduct was not supported by the data.

\section{THE DETAINED SUBJECTS}

The results from the analysis including the detained subjects indicate that detained subjects: have more prior arrests and convictions than released subjects $(6.3 \%$ and $3.5 \%$ vs. 2.38 and 1.24 ), are more likely to be unemployed than released subjects $(43.6 \%$ vs 35.7$)$. In addition, detained subjects were much more likely to be on probation 
or parole $(69 \%$ vs $19 \%)$, and to have been charged with probation violations or FTA's (65.4\% vs $17.6 \%)$.

The detention policy that emerges clearly indicates a preference to hold probationers and parolees. The data indicate that no person charged with crimes against public morality (sex abuse, public indecency) was detained pending trial. In addition, though $35 \%$ of the sample were charged with assaultive crimes, those subjects represented $9.1 \%$ of the detained subjects. This policy, however implicit, may support the assertion that pretrial detention may be used as pretrial punishment (Toborg, 1981). Probationers and parolees may be uniquely qualified for this sanction, as they are both convicted (of the original charge) and pretrial (regarding the probation/parole violation.

Comparing the frequency of detained and released subjects in each of the 16 typlogies indicated that the two groups varied significantly $\left(\mathrm{X}^{2}=36.6, \mathrm{~d} . \mathrm{f} .=15, \mathrm{p}<\right.$ $.005)$. The distribution of the detained subjects along the typologies indicates that $31 \%$ of the subjects lie in the top 8 (higher risk) typologies, as opposed to $7.8 \%$ for the released subjects. There appears to be considerable discrimination by the Washington county release office and jail staffs to identify high and low risk defendants.n 
However, the data indicate that there are opportunities for the pretrial release program to increase the number and types of persons released without increasing the misconduct rate.

The data did not support the hypothesis that probationers and parolees would pose higher risks of pretrial misconduct. The insignificance of this effect may have been due to the high detention rate of this group noted in this study. This detention rate may have created a sample that was not representative of this group. The variable of probation/parole status does not indicate the degree of past association with the criminal justice system; moreover, the high detention rate may explain why variables such as prior arrests and convictions did not prove to be significant in the model. 
CHAPTER IX

\section{CONCLUSIONS AND RECOMMENDATIONS}

The predictive model of pretrial misconduct developed in this study successfully identified high risk typologies. These typologies may be used as a framework from which release decisions may be derived. In addition, the predictive model is conducive to an expedient assessment of risk .

The finding that age, employment, and prior FTA are good predictors of pretrial misconduct affirms previous efforts (Toborg, 1981; 1989). This study made no attempt to qualitatively assess the variables that ultimately made up the model, although such an examination may explain the interactions between these variables and pretrial misconduct. The results do not reject the assumption by Sturz (1962), that persons with strong ties to the community (employment), and little prior contact with the criminal justice system (prior FTA's), would be less likely 
to engage in pretrial misconduct. The results reject the hypothesis that non-violent offenders may pose greater risk of pretrial misconduct; however, an alternate hypothesis, that younger offenders may pose a higher risk of pretrial misconduct is not rejected.

The study found that detained subjects were being detained along criteria that were related to the incidence of pretrial misconduct. In addition, the results indicated that there is a tendancy to detain probation/parole violators at the expense of releasing offenders charged with assaultive or sexual crimes. The results suggest that a modification of this policy may result in a reduction in the pretrial misconduct rate.

The current study is one of several that has sought to examine pretrial misconduct in a manner beneficial to corrections officials. The current study has provided a framework from which a comprehensive release and detention policy can be developed. In addition, the difficulties experienced in this study may serve to recommend strategies for further research. Towards these ends, it is recommended that:

1) the predictive model be field tested, where defendants would be rank ordered based on the typologies developed and maintajing file information on pretrial behavior. 
The field testing would serve to provide a more accurate assessment of the model's validity. In addition, the database created by this testing may apprise corrections officials of the need to maintain pretrial release and detention data. The difficulty in conducting such research, due to the lack of such a database, may explain why few studies of this nature are undertaken. In addition, field testing would be imperative should the model be utilized in another jurisdiction. Toborg (1981; 1989) has emphasized that interjurisdictional difEerences such as urban/rural, amount of jail space, types of crime, and demographics, may impact the utility of a model. This study's basis on Washington county data should be considered applicable only for washington county. Generalization of these results to other areas should be preceeded by field testing the model in that jurisdiction.

2) Stratified samples be used in further studies. Samples stratified by crime type or age may alleviate some of the problems with small cell frequencies found in this study. In addition, the relationship between crime type and pretrial misconduct may be more evident using this type of sample. 
3) creative measures to reduce pretrial misconduct be explored, such as having pretrial monitoring, where either a defendant calls in periodically or is called to be reminded of a court appearance. Toborg (1981) has found that these methods have reduced pretrial misconduct rates and are generally cost-effective. The emergent detention policy suggests that pretrial detention may be based on factors other than risk of pretrial misconduct. Thus, real reductions in pretrial misconduct may require more proactive policies. 


\section{REFERENCES}

Advisory Commission on Intergovernmental Relations,

$(1984)$ Jails: Intergovernmental dimensions of a local problem. Washington D.C..

Allen, M. J., \& Yen, W. M., (1979). Introduction to Measurement Theory. Brooks/Cole: Monterey, California.

Aronson, E. (1984). The Social Animal (4th Ed.). W.H. Freeman \& Co.: New York.

Barley, w. (1984). Poverty, inequality, and city homicide rates: some not so unexpected findings. Criminology, 22, 531-550.

Benda,B. B. (1989). Predicting return to prison among adolescent males: A comparison of three statistics. Journal of Criminal Justice, 17, 487-500.

Blau, J. R. \& Blau, P. M. (1982). The cost of inequality: Metropolitan structure and violent crime. American Sociological Review, 47, (Feb), 114-129.

Cargill, L. (1986). "Jail space awaits people offenders, Probstfield says". The Oregonian, August 2, 1986, C3.

Clear, T. R. \& Cole, G. F. (1986). American

Corrections. Brooks/Cole: Monterey, California.

DeFronzo, J. (1983). Economic assistance to impoverished Americans. Criminology, 21, (1), 119-136.

Eysenck, H. J., (1964). Crime and Personality. Houghton and Miflin \& Co.: Boston, Massachusetts. 
Farrington, D. P., \& Tarling, R. (1985). Criminological prediction: An introduction. In, Farrington, D. P., \& Tarling, Roger (Eds), Prediction in criminology. State University of New York Press: Albany, New York York.

Flango, V., \& E. Sherbonou. (1976). Poverty, urbanization and crime. Criminology, 14, 331-346.

Fuchs, C. \& Flanagan, J. (1980). Step-wise fitting of logit models with categorical predictors in the analysis of parole outcome. Journal of Research in Crime and Delinguency, 17, $(\underline{2}), 273-279$.

Gibbons, D. C. (1983). Mundane Crime. Crime and Delinquency,29, (ㅁ) , 213-227.

Gottfredson, M. R., (1974). An empirical analysis of pretrial release decisions. Journal of Criminal Justice, 2, 287-304.

Hogan, R. (1982). A socioanalytic theory of personality. In M. Page and R. Dienstibier (Eds), Nebraska Symposuim on Motivation. University Press: Lincoln, Nebraska.

Hogan, R., \& Jones, W. H., (1983). A role theoretical model of criminal conduct. In Laufer, $W$. $S$. and Day, J. M. (Eds). Personality Theory, Moral Development, and Criminal Behavior. D.C. Heath \& Co.: Lexington, Massachusetts.

Homer, E. L., (1984). Inmate-family ties: Desirable but difficult. Federal Probation, 43, (1), 47-52.

Jones, J. \& Gibbons, D. C., (1983). Deviance and Diversity: Notes on an emerging perspective. Unpublished manuscript: Portland state University.

Kennedy, J. J. (1983). Analyzing qualitative data: Introductory loglinear analysis for behavioral research. Praeger: New York, New York. 
Merton, R. K. (1968). Social structure and anomie. In Robert $K$. Merton (Ed) Social Theory and Social Structure. Erie Press: New York, New York.

Morris, N. \& Miller, M., (1985). Predictions of dangerousness. In Nagel, I. H., \& Hagen, J. (Eds), Crime and Justice: An annual review of research. Vol. 6. University of Chicago Press: Chicago.

National Association of Pretrial Services Agencies. (1978) Pretrial Release: Performance Standards and goals for Pretrial Release and Diversion. Authors: Washington, D.C..

Oregon Law Enforcement Council \& Law Enforcement Data systems (1988). Analysis of Crime in Oregon. state of Oregon.

Ott, M. D., \& Markewich, T. S., (1985). Logit Analysis of Graduate student Retention and Graduation Paper presented at Association of Institutional Research: Portland, Oregon.

Pretrial Services Resource Center (1988). "Jail inmate populations increase". Prerial Reporter, 7, (ㅇ), pg. 10 .

Pretrial Services Resource Center (1990). National Report. January 1990. Washington D.C.

Pryor, D. E., and Smith, W. F., (1982). Significant research findings concerning pretrial release. Pretrial Release, 4, (1), Feb., 1-16.

Sturz, H. (1962). An alternative to the bail system. Federal Probation, 26, (4) , 49-53. 
Toborg, M. A. (1981). Prerial release: A national evaluation of practices and outcomes. National Institute of Justice: Washongton, D. C..

Toborg, M. A. (1989). Development of empirically based pretrial release guidelines for the state of oregon. (Unpublished research). Landover, Maryland.

United states Department of Justice. (1985). Pretrial Release and Misconduct. Bureau of Justice statistics: Washington D.C..

United States Department of Justice. (1987). Jail Inmates. Bureau of Justice statistics: Washington D.C..

United states Department of Justice. (1988). Report to the Nation on Crime and Justice. Bureau of Justice Statistics: Washington D.C..

Van Alstyne, D. J., \& Gottfredson, M. R. (1978).

A multidimensional contingency table analysis of parole outcome: New methods and old problems in criminological prediction. Journal of Research in Crime and Delinquency, 15, () , 172-193. 
APPENDIX A

POPULATION RELEASE SCORES 
WASHINGTON COUNTY JAIL

POPULATION RELEASE SCORES

Name:

Book\#

Date

Highest Ranking charge score ................

\section{Companion Charges}

Each nonviolent Misd/Major Traffic

Each nonviolent Felony

Each violent Misdemeanor

Each violent Felony

Charge modification points
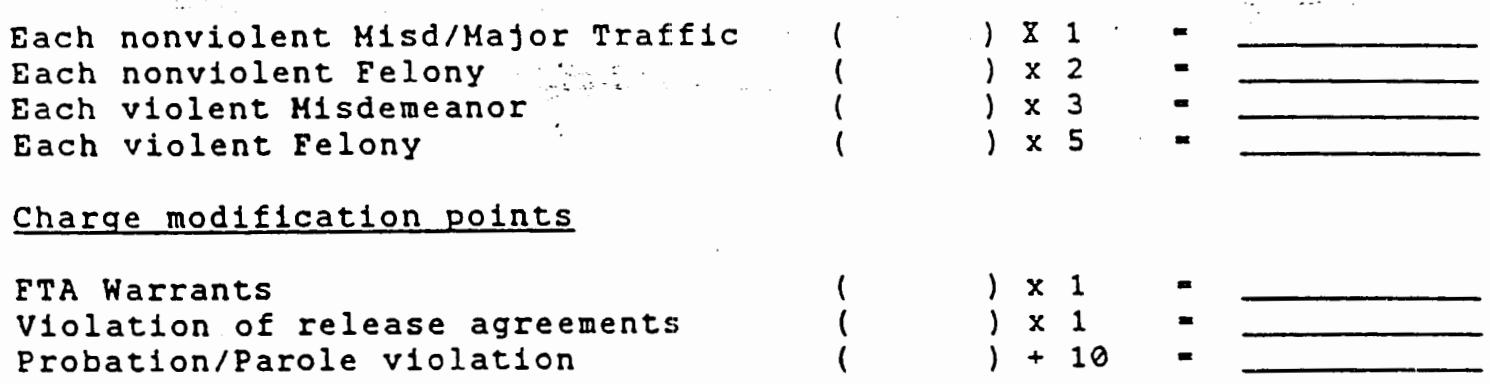

custody \& classification points

Assaultive;Disruptive;Escape riskiUnstable or Unpredictable ( 10 points - any or all)

Return from R.C/Remove Trusty (Add 40 points)

Major Psychological problem (A.... (Add 40 points)

Gang membership $\ldots$ (Add 30 points)

7 Close custody

8Max custody

(Add 10 points)

(Add 50 points)

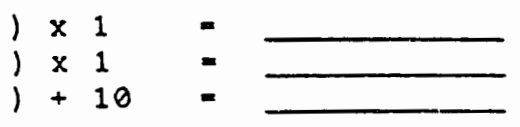

Criminal History points

ardorats

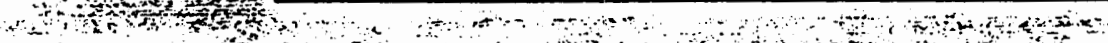

Violent Misd

Violent.Fel

Prob V1o

Parole Vio

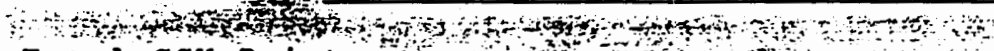

Total CCH Points

Exceptional Danger Hold

yes

no

Narrative Explanation

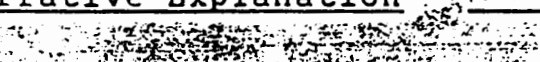

man

10.

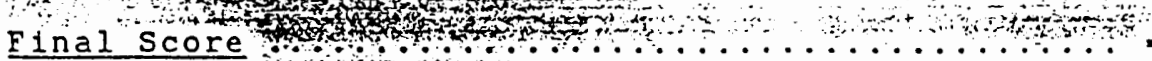
and

Reviewer:

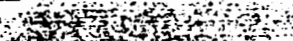

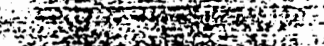

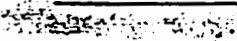
BPST Date 
APPENDIX B

RECOGNIZANCE AGREEMENT 


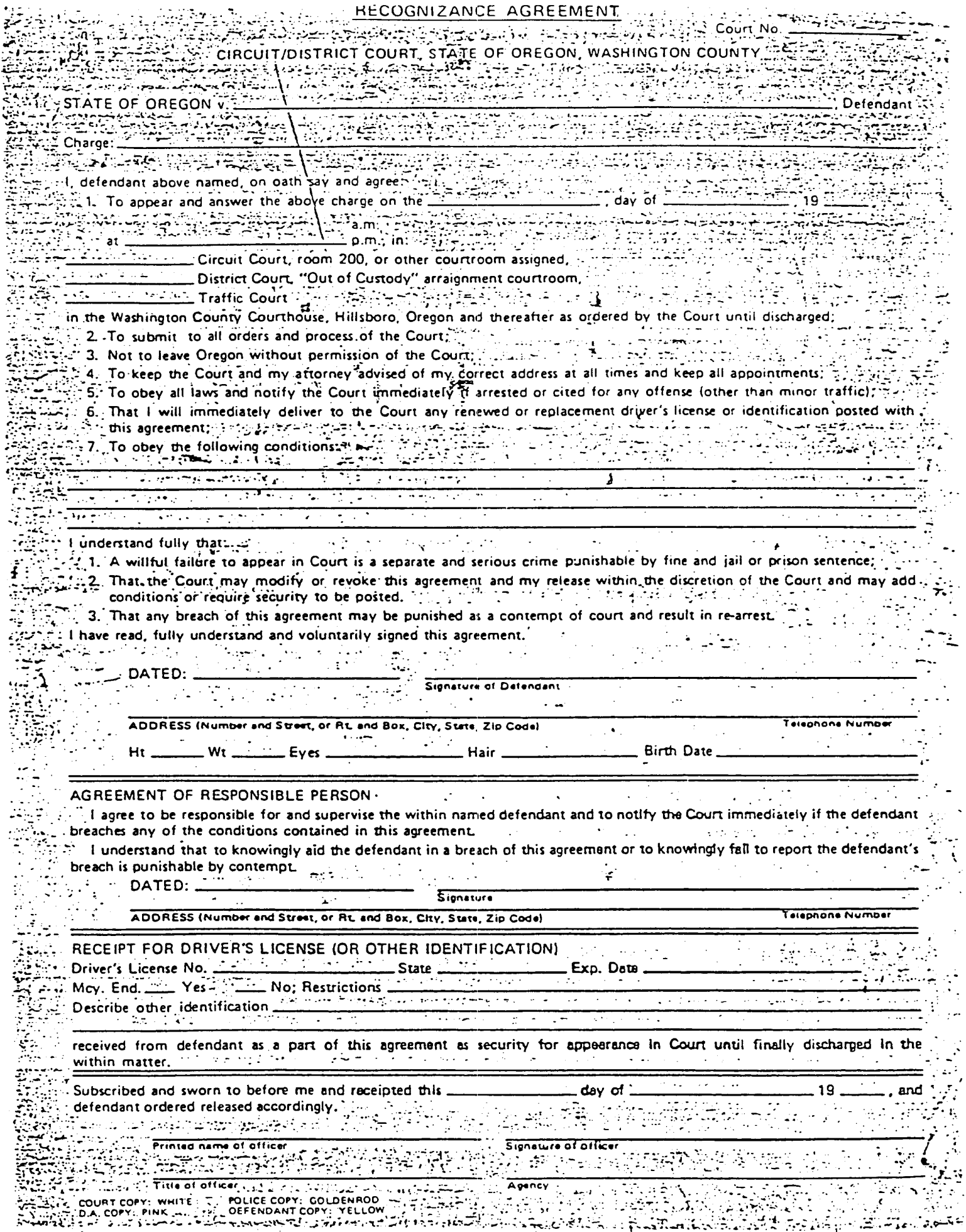




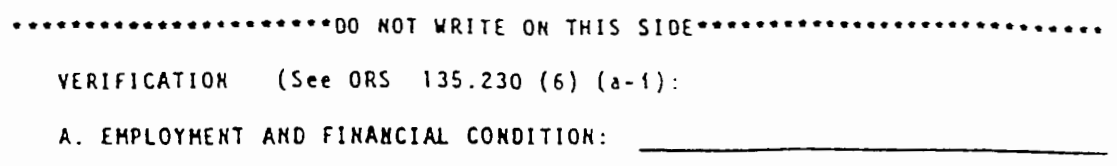

2. EMPLOYMENT AND FikAMCIAL CONDITION:

B. FAMILY RELATIONSHIPS:

C. PAST AND PRESEHT RESIDENCES:

D. PERSONS WHO HILL ASSIST DEFENDANT:

E. NATURE OF THE CHARGE:

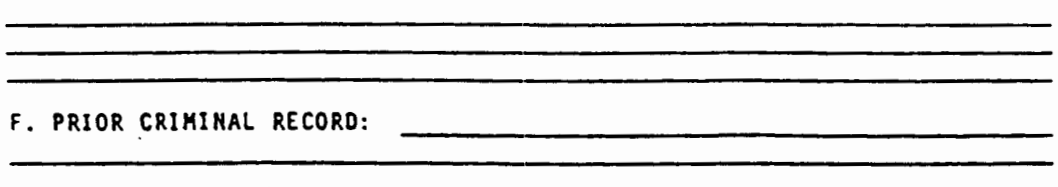

G. POSSIBLE VIOLATION OF LAK IF DEFEMOANT IS RELEASED:

H. COMMUKITY CONTACTS:

\section{O: OTHER FACTS:}
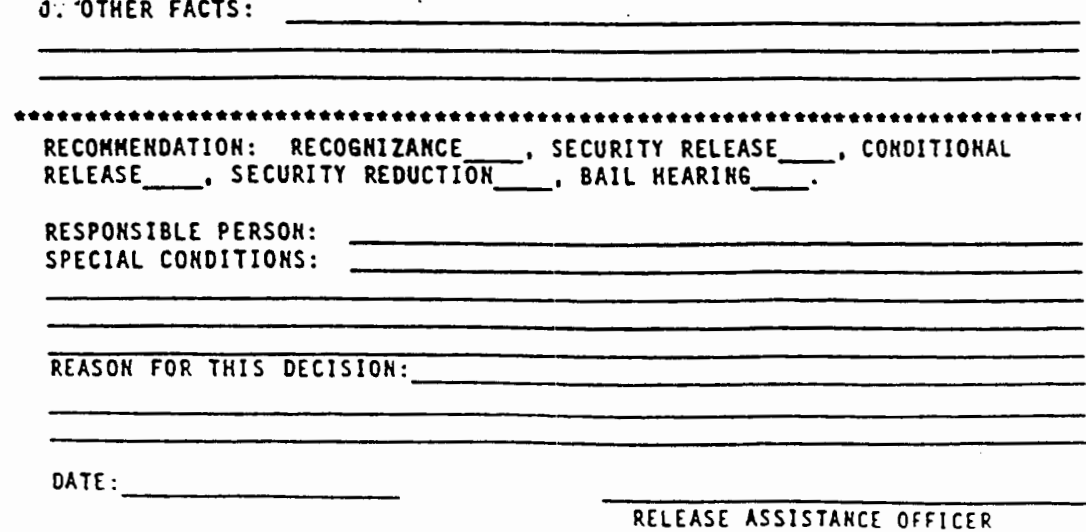
APPENDIX C

INITIAL RISK ASSESSMENT 


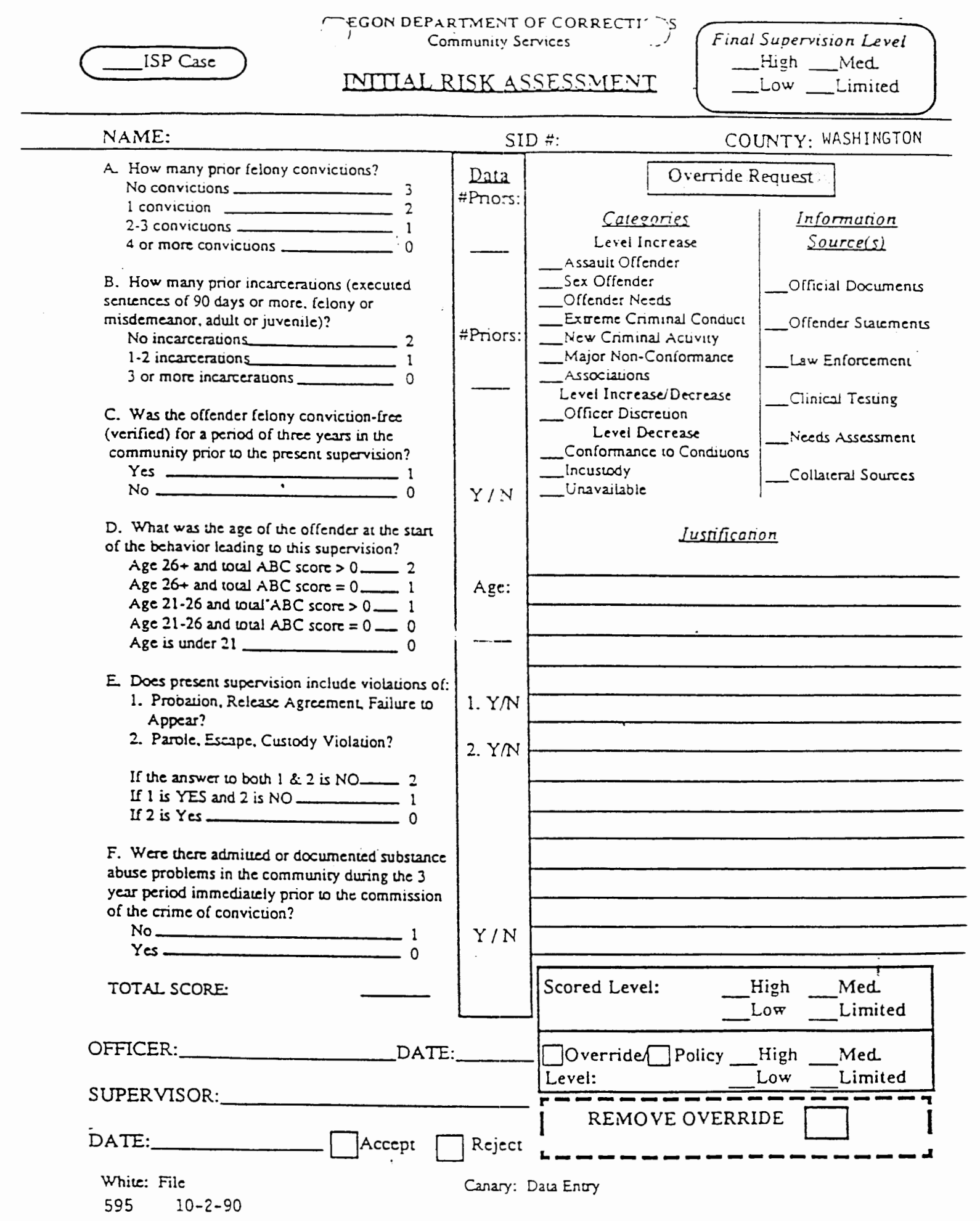


APPENDIX D

DATA COLLECTION FORM 
Data Collection Form

Name (for tracking only) | Sex! Ethnic| Agel NPRA I NPRC!

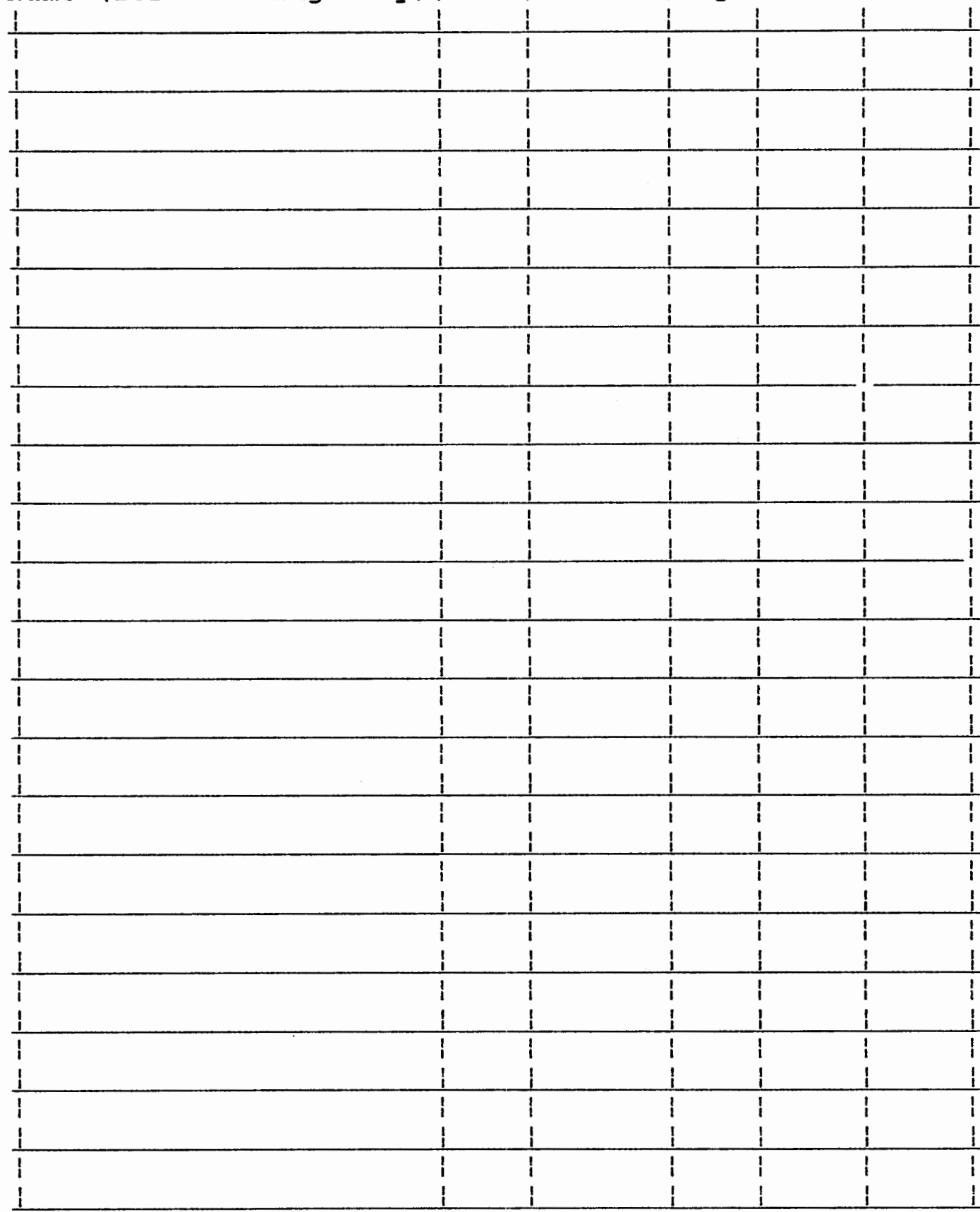


Data Collection Form

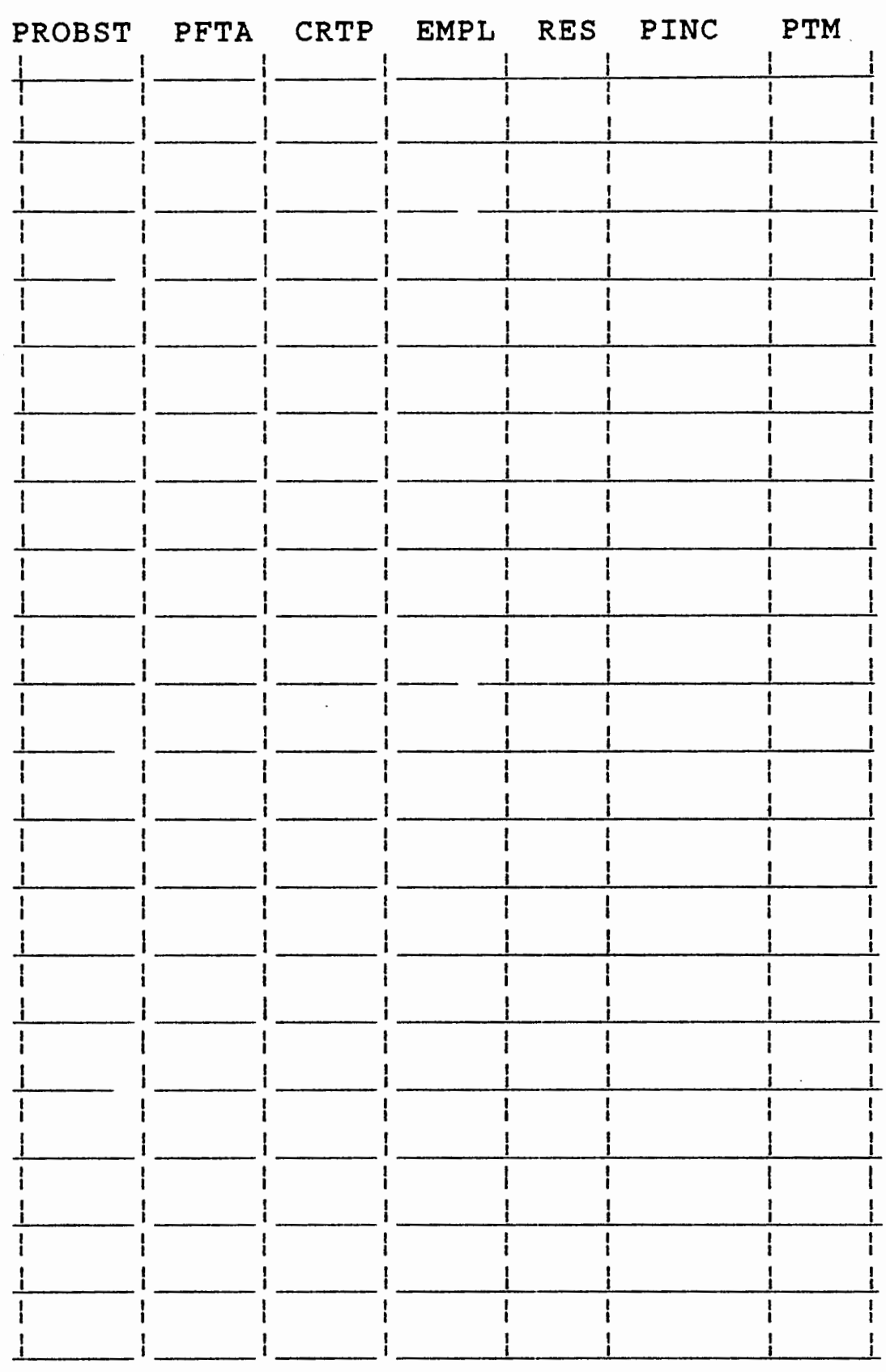

